\title{
CICLOESTRATIGRAFIA DO EOPERMIANO - ESTUDO DE CASO NO GRUPO ITARARÉ, BACIA DO PARANÁ (PARTE 1): UMA METODOLOGIA PARA PRE- PARAÇÃO DE DADOS DE PERFIL E ROCHA
}

\author{
JOSÉ GUILHERME RODRIGUES DA SILVA ${ }^{1}$, NILO CHAGAS DE AZAMBUJA FILHO ${ }^{2}$
}

\begin{abstract}
CYCLOSTRATIGRAPHY OF LOWER PERMIAN - CASE STUDY IN ITARARÉ GROUP, PARANÁ BASIN (PART I): A METHODOLOGY FOR LOG AND ROCK DATA PREPARATION This study presents a methodology of data preparation for cyclostratigraphic analysis, using core and gamma ray log data from two wells drilled by CPRM (Companhia de Pesquisa de Recursos Minerais) to coal research, one in Santa Catarina state (7-RL-04-SC) and other in Rio Grande do Sul state (IB-93-RS). The wells sampled rocks from Lower Permian Itararé Group, Paraná Basin, originally deposited in glacial, periglacial and marine environments. The distance between the original locations of the cores (about $380 \mathrm{~km}$ ) made it possible to test, afterward (Cyclostratigraphy of Lower Permian - Case Study in Itararé Group, Paraná Basin (PART II), in this same publication), the astronomic forcing in different locations of the basin. Two methods of data sampling were used, according to data scale and the possible forcing: the gamma ray logs were digitized and sampled at $1 \mathrm{~cm}$ intervals, in order to test the presence of orbital forcing $(20,000$ to 400,000 years) or other forcing phenomena (3,000 to 10,000 years), and the cores were scanned in the intervals with rhythmites and transformed in gray scale data sampled equally $(0.2538 \mathrm{~mm})$, in order to search for annual to millenarian cycles. The process of core data preparation before scanning required a detailed elimination of small fractures and sedimentary structures as ripples, to avoid distortions in the final results.
\end{abstract}

Keywords: cyclostratigraphy, Itararé Group, Lower Permian.

\begin{abstract}
Resumo Este trabalho apresenta uma metodologia de preparação de dados para análise cicloestratigráfica. Foram utilizados testemunhos e perfis de raios gama de dois poços que amostraram rochas do Grupo Itararé, Eopermiano da Bacia do Paraná, originalmente depositadas em ambiente glacial, periglacial e marinho. Os poços, um em Santa Catarina (7-RL-04-SC) e outro no Rio Grande do Sul (IB-93-RS), foram perfurados pela CPRM para pesquisa de carvão mineral e a distância entre eles (cerca de $380 \mathrm{~km}$ ) possibilitou testar, posteriormente (Cicloestratigrafia do Eopermiano - Estudo de caso no Grupo Itararé, Bacia do Paraná (Parte II), nesta mesma edição), a influência da indução astronômica em localidades distintas da bacia. Dois métodos de amostragem foram utilizados, de acordo com a escala dos dados e com a possível indução:os perfis de raios gama foram digitalizados e amostrados em intervalos de $1 \mathrm{~cm}$, para testar a presença dos ciclos orbitais na escala de 20 mil a 400 mil anos, ou outros fenômenos indutores na escala de 3 mil a 10 mil anos, e os testemunhos foram escaneados nos intervalos com ritmitos e transformados em dados em escala de cinza equiespaçados $(0,2538 \mathrm{~mm})$, objetivando a busca por ciclos anuais a milenares. A preparação dos dados dos testemunhos para a digitalização no scanner necessitou de um tratamento minucioso de eliminação, nas imagens, de pequenas fraturas e estruturas sedimentares, tais como ripples, para que as mesmas não comprometessem o resultado final.
\end{abstract}

Palavras-chave: cicloestratigrafia, Grupo Itararé, Eopermiano.

INTRODUÇÃO Dados litológicos ou derivados de rochas (geoquímicos, abundância de fósseis, etc.) podem ser convertidos em valores numéricos a partir da codificação ou da subdivisão em pequenos intervalos para os quais são calculadas porcentagens, permitindo assim a análise através de séries temporais (Schwarzacher, 1987; Cottle, 1989; Azambuja Filho, 1990). A mesma conversão pode ser realizada a partir de dados de perfis elétricos, onde a grandeza medida é a distância entre os picos de amplitude (espessura das variações litológicas) na curva do perfil. Outra forma de transformar informações litológicas em valores numéricos é a utilização do scanner. Escanear um trecho de testemunho significa transformar as diferenças de coloração e espessura das camadas em dados digitais, ou seja, valores numéricos (Shaaf \& Thurow 1994, Pike \& Kemp 1996). Esses dois últimos métodos foram utilizados na obtenção dos dados desse estudo, representando, porém, escalas de trabalho distintas: os perfis tendem a mostrar as mudanças de larga escala, relacionadas às variaçôes relativas do nível do mar. Os testemunhos, além dessas, registram também variações climáticas de mais alta frequiência. Trabalhar nas duas escalas possibilita a identificação de forma mais completa dos mecanismos de indução externa atuaram na sedimentação. Esse artigo e o denominado "Cicloestratigrafia do Eopermiano - Estudo de caso no Grupo Itararé, Bacia do Paraná (Parte II): evidências de indução astronômica (orbital e solar) no clima e na sedimentação" (a partir daqui denominado CEGI-2), nessa mesma publicação, são o resultado do estudo da influência desses mecanismos nas oscilações e variações cíclicas climáticas e dos efeitos das últimas na sedimentação (Silva 2001).

Foram escolhidos dois testemunhos com registros expressivos de ritmitos e folhelhos das rochas do Grupo Itararé, provenientes de dois poços perfurados pela Superintendência Regional do Rio Grande do Sul da CPRM (Companhia de Pesquisa de Recursos Minerais) para a exploração de carvão mineral. Os poços foram selecionados também por suas posições geográficas distantes (aproximadamente $380 \mathrm{~km}$ ), para tentar observar a indução astronômica em locações distintas da bacia. A localização dos testemunhos se encontra na figura 1. São eles:

7-RL-04-SC (Projeto Rio Laranjeiras número 4), perfurado em 1979 em Anitápolis, Santa Catarina. Coordenadas UTM = $6919350 \mathrm{~m} ; 673620 \mathrm{~m}$. Folha SG-22-Z-C-VI. Possui $191 \mathrm{~m}$ de rochas do Grupo Itararé.

IB-93-RS (Projeto Irui-Butiá número 93), perfurado em 1981 em Butiá, Rio Grande do Sul. Coordenadas UTM $=6667000$ 
m; 389000 m. Folha SH-22-Y-B-I. Possui $71 \mathrm{~m}$ de rochas do Grupo Itararé.

GRUPO ITARARÉ As rochas do Grupo Itararé (Gordon 1947 apud França \& Potter 1988), nos estados de Santa Catarina e do Rio Grande do Sul, possuem idade Eopermiana (Daemon \& Quadros 1970, Cazzulo-Klepzig et al. 1980, Marques-Toigo et al. 1989, Lopes et al. 1991, Marques-Toigo 1991, Dias 1993a, Dias 1993b, Guerra-Sommer \& Cazzulo-Klepzig 1993), representando deposição em ambiente glacial, periglacial e marinho (Castro 1980, Tomazelli \& Soliani Jr. 1982, Aboarrage \& Lopes 1986 apud Lopes 1995, Marques-Toigo et al. 1989, Machado 1989, Castro 1991, Castro e Schneider 1993, Canuto 1993, Dias 1993a, Dias 1993c, Machado 1994, Castro 1995, Lopes 1995, Holz 1995a, Holz 1995b, Santos et al. 1996, Silveira, 2000).

ANÁLISES QUANTITATIVAS DE CICLOS SEDIMENTARES As variações periódicas da órbita da Terra ao redor do Sol foram quantificadas primeiramente por Milankovitch em 1941. Os ciclos induzidos por essas variações atualmente são denominados de Ciclos de Milankovitch, e eles têm três prin-

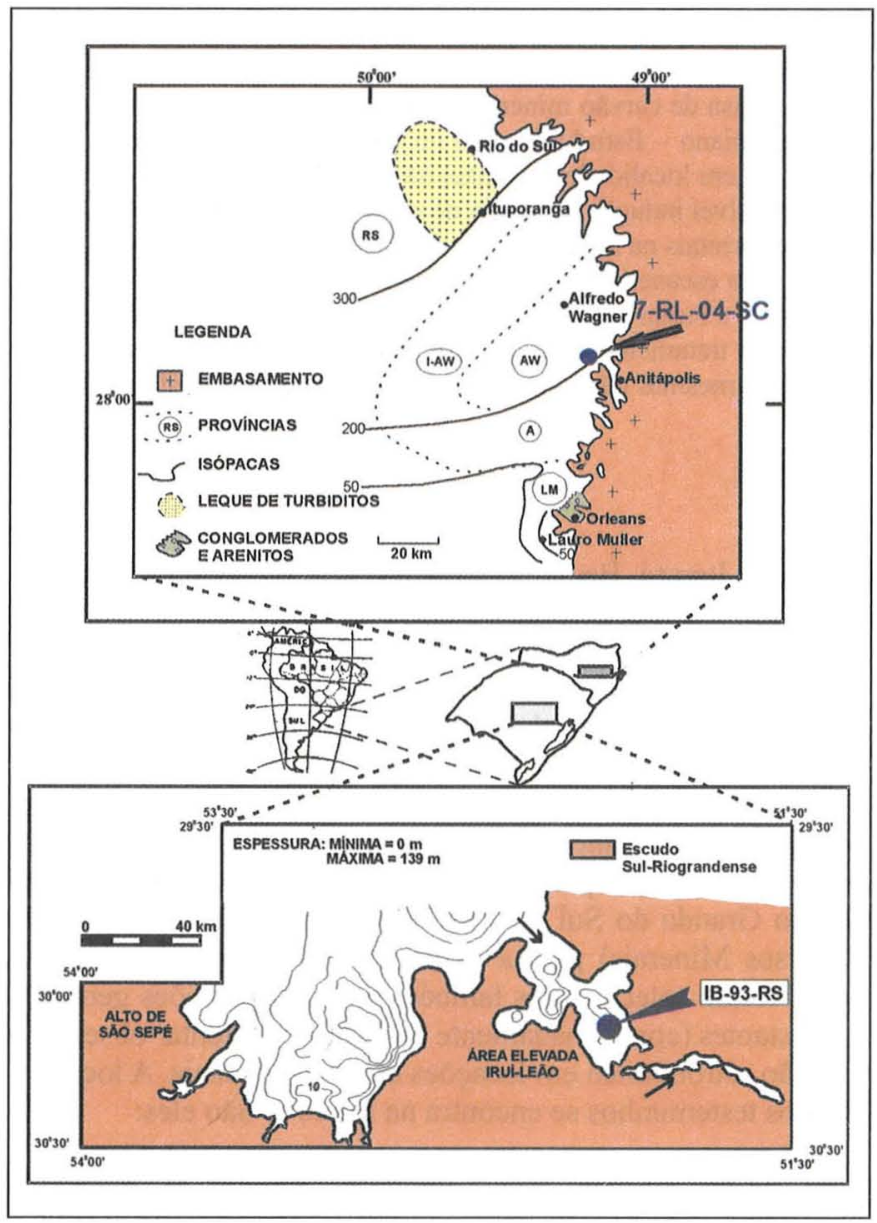

Figura 1 - Mapas de localização e de isópacas. Mapa superior: contexto geológico onde se insere o testemunho 7-RL04-SC, na unidade superior do Grupo Itararé, em Santa Catarina, segundo Castro (1991), e as provincias definidas por esse autor: $R S=$ Rio do Sul; $I-A W=I t u p o r a n g a-A l f r e d o$ Wagner; $A=$ Anitápolis; $A W=$ Alfredo Wagner; LM=Lauro Miller. Mapa inferior: região dos paleovales de Capané, Leão e Leão-Mariana Pimentel, preenchidos por rochas do Grupo Itararé (Lopes 1995). O poço IB-93-RS está inserido no contexto geológico do paleovale Leão. cipais componentes relacionados a aspectos da órbita e inclinação do eixo da Terra, o que afeta a recepção e distribuição do calor oriundo do Sol: excentricidade, obliqüidade e precessão. A órbita da Terra ao redor do Sol é elíptica e possui duas principais variações da sua órbita as quais possuem periodicidades de aproximadamente $413 \mathrm{Ka}$ e $100 \mathrm{Ka}$. A obliqüidade, ou seja a variação do grau de inclinação do eixo da terra em relação a sua órbita ao redor do Sol tem uma periodicidade de aproximadamente $41 \mathrm{Ka}$. A precessão dos equinócios muda progressivamente a medida em que as estações mudam em função da posição relativa da órbita da Terra ao redor do Sol, possui duas principais periodicidades $19 \mathrm{Ka}$ e $23 \mathrm{Ka}$. Segundo Matthews and Frohlich (1991), devido à interferência desses ciclos, estima-se que possam ser gerados ciclos climáticos de longo período os quais poderiam atingir algo em torno de $2.4 \mathrm{Ma}$. Maiores detalhes serão discutidos mais adiante neste artigo.

No Rio Grande do Sul, a borda do Escudo Rio-Grandense é cortada por várias sub-bacias, interpretadas como paleovales ou paleofiordes (Aboarrage \& Lopes 1986 apud Lopes 1995, Holz 1995a, Santos et al. 1996), preenchidas pelas rochas do Grupo Itararé, que se alargam em direção à Bacia do Paraná. Suas dimensões variam de centenas de metros a poucos quilômetros até depressões de 90 quilômetros de largura por 160 metros de profundidade (Santos et al. 1996), preenchidas por seqüências de fácies de fluxo de detritos (nos flancos e no fundo dos vales) interdigitadas com fácies fluviais e lacustrinas. Um desses paleovales é denominado Leão, onde se localiza o poço IB-93-RS, utilizado nesse trabalho (Dias 1993a, Lopes 1995, Holz 1995a, Santos et al. 1996, Silveira 2000) (figura 1).

Quanto à região sudeste de Santa Catarina, foi dividida em províncias por Castro (1991), seguindo as características deposicionais presentes no Eopermiano, sendo denominada província de Alfredo Wagner aquela onde se localiza o poço 7-RL-04-SC (figura 1), a qual teria agido como um centro de glaciação ativo, devido à permanência das condições glaciais. Os sedimentos do Grupo Itararé na região estão representados, na base, por camadas delgadas de tilitos de alojamento, depositados sobre uma superfície erosiva esculpida pelo gelo, sobrepostas por varvitos e diamictitos de fluxo. Esses últimos diminuem gradualmente de espessura, sendo cobertos por folhelhos marinhos. Acima, ocorrem arenitos de leques de lavagem subaquosos, recobertos por diamictitos, arenitos e siltitos capeados por varvitos, folhelhos e siltitos. Essa associação indica que o nível relativo do mar variou de acordo com o avanço e recuo das condições glaciais (Machado 1989, Castro 1991, Castro e Schneider 1993, Canuto 1993, Castro 1995, Santos et al. 1996). Segundo Machado (1989), Castro (1991) e Santos et al. (1996), essas seqüências depositaram-se em reentrâncias ou inlets costeiros isolados, em certos períodos, pelas oscilações do nível do mar.

METODOLOGIA Uma série temporal de sedimentos ou rochas sedimentares pode ser construída a partir de uma amostragem contínua, coletada a intervalos iguais (Schwarzacher, 1987). O intervalo de amostragem (IA) em espessura, segundo a teoria da amostragem (Weedon 1991, Chatfield 1989), deve ser tal que o comprimento de onda de interesse, ou seja, a menor espessura amostrada, contenha pelo menos dois intervalos de amostragem.

Imagens digitais são formadas por porções, ou celas, que formam uma matriz com endereços cartesianos X e Y definidos, com origem no canto superior esquerdo. Cada cela recebe o nome de pixel e possui um atributo numérico denominado número digital que corresponde à média da intensidade de energia refletida ou emitida pela imagem no pixel (Rossetti 1996). Adquirindo-se uma imagem amostrada em 8 bits, os valores do número digital para cada pixel representam diferentes tons de 
cinza, variando entre 0 e 255 (256 valores, sendo 0 correspondente a branco e 255 a preto).

É necessário, portanto, que a dimensão de cada pixel seja compatível com a amostragem que se deseja fazer, ou seja, no mínimo, a metade da dimensão da menor camada observada. Da mesma forma, os atributos da rocha precisam ser levados em conta. No caso dos ritmitos estudados, formados por intercalações de siltito e folhelho, as variações de coloração se encontram na faixa do espectro de tons de cinza, perfeitamente reproduzíveis na escala de 0 a 255 .

Dados dos testemunhos A premissa básica para a escolha dos testemunhos foi a presença de ritmitos, de forma a possibilitar o teste da ocorrência de alguma periodicidade, fosse ela anual (varvitos), como sugere grande parte da literatura sobre o Grupo Itararé, ou outra periodicidade qualquer. Os trechos de testemunho trabalhados possuem espessura total de ritmitos compatível com o objetivo do trabalho. Outro fator impositivo foi a ausência de estruturas sedimentares que implicassem em variação na espessura de cada lâmina rítmica individualmente (por exemplo, ondulações) e na conseqüente distorção dos resultados. Conseqüentemente, o topo das lâminas dos ritmitos foi considerado praticamente plano para distâncias laterais consideráveis, relativas ao contexto do ambiente em que foram depositados. As profundidades apresentadas no texto são as medidas originalmente, pela CPRM, quando da amostragem dos testemunhos.

DESCRIÇÃO DOS TESTEMUNHOS A análise por séries temporais dos dois poços, descrita em artigo nessa mesma revista (CEGI-2), foi feita utilizando-se os perfis elétricos e os trechos dos testemunhos. O estudo foi dividido, então, em duas escalas de trabalho distintas: uma maior, a dos testemunhos, e outra menor, a dos perfis, sendo que descrições mais detalhadas resumem-se aos trechos de testemunho escaneados e utilizados para a análise (290,08 a 290,46 m para o testemunho IB-93-RS e de 525,47 a $526,70 \mathrm{~m}$ para o testemunho 7-RL-04-SC).

Para o poço IB-93-RS foram feitas também descrições simplificadas de toda a seção, desde a base até a profundidade de $290,82 \mathrm{~m}$

Testemunho do poço 7-RL-04-SC O intervalo escaneado do poço em questão $(525,47$ a $526,7 \mathrm{~m})$ possui uma espessura total de 1,23 m, sendo formado por pares de lâminas alternadas de siltito cinza claro e folhelho cinza escuro, caracterizando uma

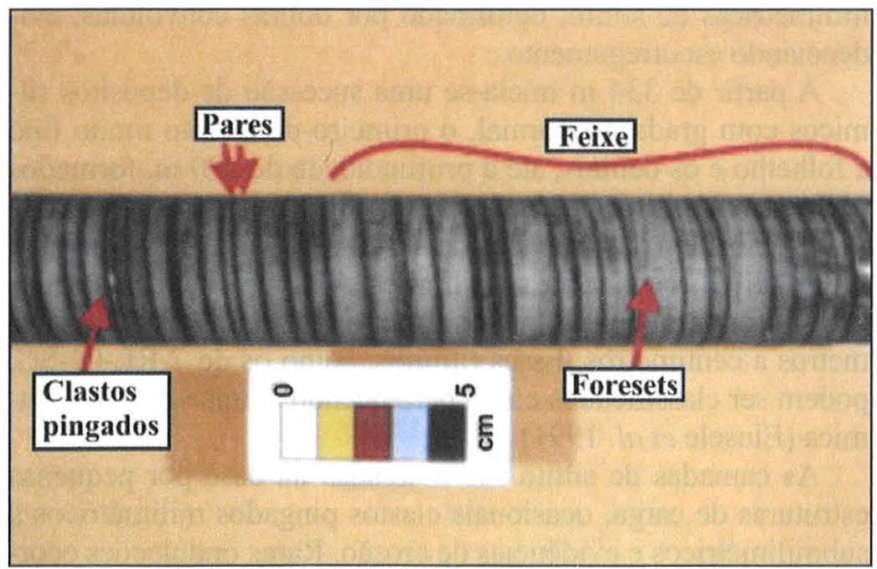

Figura 2 - Fotografia de parte do testemunho 7-RL-04-SC. Pode-se ver a ritmicidade dos pares de laminas de siltito e folhelho formando feixes. Notar as ripples unidirecionais e alguns clastos pingados. seqüência rítmica (Einsele et al. 1991) (figura 2). O contato entre as lâminas de siltito e folhelho é abrupto. Não foram obser-

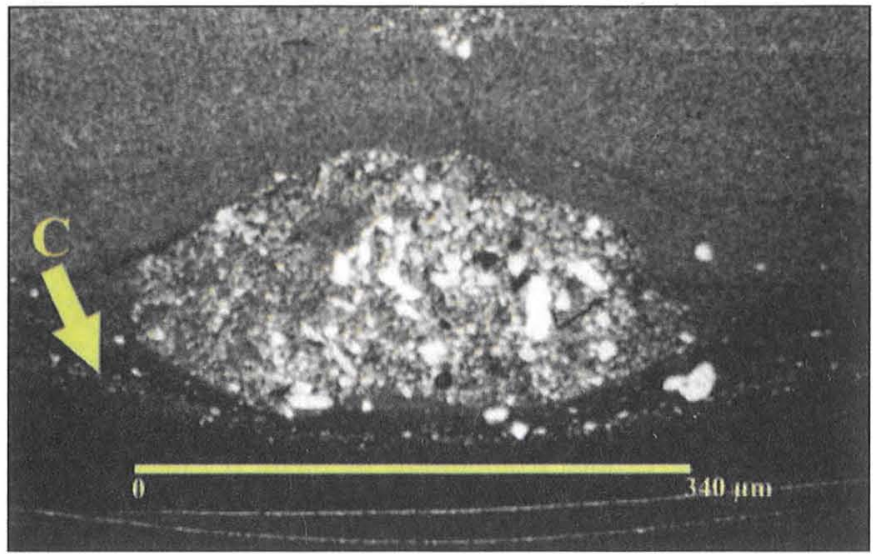

Figura 3 - Fotomicrografia mostrando um clasto pingado de arenito pouco litificado intrabacinal, amoldado e suavemente estirado devido à compactação. Notar a chuva de detritos na base da lâmina de siltito $(C)$.

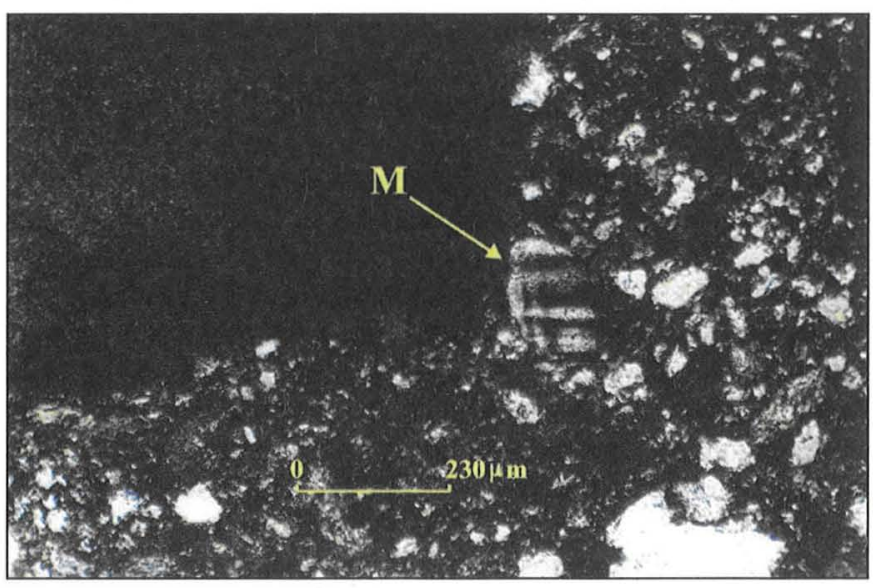

Figura 4 - Fotomicrografia do interior de um clasto pingado. Detalhe do grão $(M)$ de microclínio $(230 \mathrm{~mm})$. Nicóis cruzados.

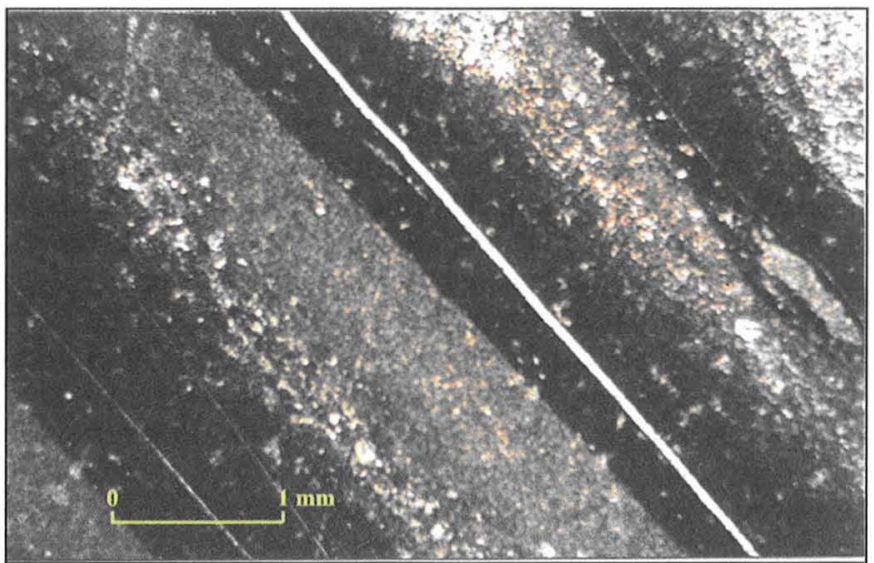

Figura 5 - Fotomicrografia (topo para a direita). Notar a passagem abrupta das lâminas de siltito (claras) para as de folhelho e a extinção conjunta dos argilominerais nos folhelhos: preservação da orientação original de deposição. Nicóis cruzados. 


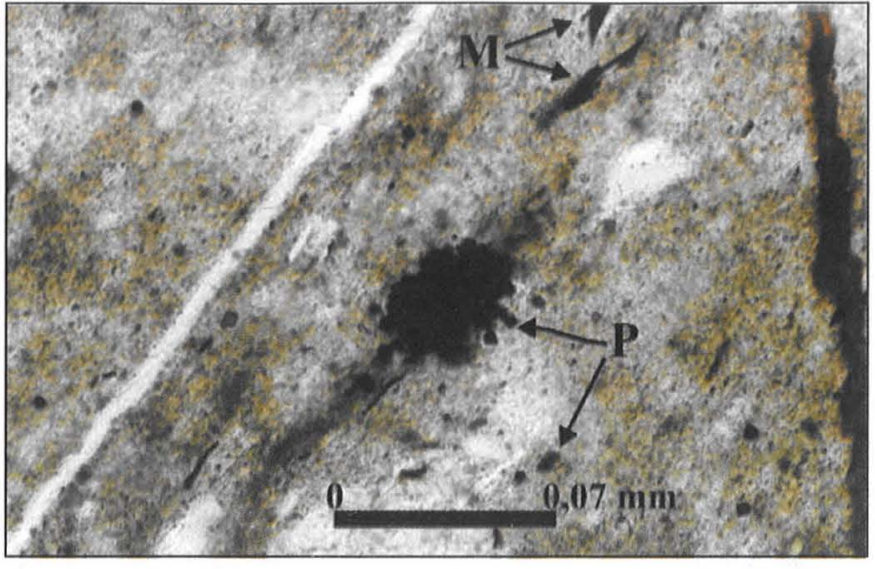

Figura 6-Agregados framboidais de pirita $(P)$ disseminados em lâmina de siltito. A lâmina mostra também intraclastos de matéria orgânica (M) e uma fratura preenchida por carbonato. Luz oblíqua (fibra ótica).

vadas bioturbações.

A espessura das lâminas de siltito varia entre $0,1 \mathrm{e} 0,5 \mathrm{~cm}$, chegando a até $1,1 \mathrm{~cm}$, e a das lâminas de folhelho de $0,1 \mathrm{a}$ $0,2 \mathrm{~cm}$ de espessura média. As lâminas de siltito apresentam internamente ripples unidirecionais com parte do foreset preservado (figura 2). A base de cada lâmina é marcada por uma fina deposição de chuva de detritos provenientes de icebergs (figura 3).

Os pares se agrupam em feixes assimétricos de três a sete pares, de espessura crescente para o topo, os quais se agrupam em feixes assimétricos maiores de até trinta pares, com as mesmas características (figura 2). Da base até o topo do intervalo escaneado existem aproximadamente 413 pares. Observa-se uma grande quantidade de clastos pingados nos ritmitos, cuja granulometria varia de areia fina a seixo. Lâminas petrográficas mostraram que esses clastos são formados predominantemente por quartzos facetados e arenitos intrabacinais pouco litificados (figura 3).

Os clastos de arenitos intrabacinais mostram contato gradacional com as lâminas do ritmito e se amoldaram com a compactação, sendo formados por grãos de quartzo, plagioclásio, alguns microclínios e por intraclastos de matéria orgânica lenhosa, rochas graníticas e folhelhos. A presença dos plagioclásios e microclínios com pouca ou nenhuma alteração caracteriza o clima seco glacial, com pouco intemperismo químico (figura 4).

As lâminas de folhelho apresentam extinção conjunta na lâmina petrográfica, caracterizando a preservação da orientação original da deposição (fissilidade primária) (figura 5).

Agregados framboidais de pirita, disseminados e na escala de micrômetros, são comuns (figuras 6 e 7). Ramos \& Formoso (1975) comentaram que o grau de diagênese parece não ser elevado nas rochas do Grupo Itararé. Os frambóides de pirita corroboram esse fato, pois são formados durante as fases iniciais da diagênese (em contraste com piritas euédricas, das fases posteriores), sob condições anóxicas, pela redução do sulfato de águas marinhas ou salobras pela ação de bactérias anaeróbicas (Raiswell 1982, Postma 1982, Bloch \& Krouse 1992). Geramse normalmente em sedimentos finos com conteúdo significativo de matéria orgânica, onde a água contida nos poros está em conexão de difusão livre com a água acima da coluna sedimentar (Postma 1982). Concentrações de sulfato dissolvido em água doce são, em média, muitas centenas de vezes menores, que na água salgada, sendo rápida e totalmente consumidas em

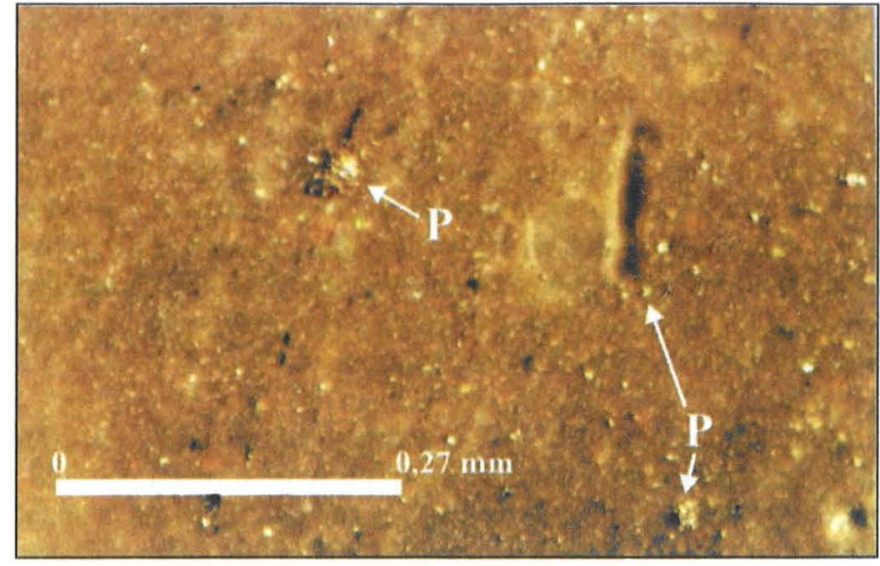

Figura 7 - Pirita framboidal disseminada brilhando em luz obliqua.

profundidades de poucos centímetros de sedimento, restando pouca pirita e muita matéria orgânica. Logo, contrastando com sedimentos marinhos, nos sedimentos de água doce o sulfato é o principal controlador da formação de pirita (Berner 1984). Portanto, a grande quantidade de pirita framboidal dos ritmitos indica que a deposição se deu em ambiente marinho ou de águas salobras.

No meio do intervalo escaneado existe uma pequena falha de rejeito quase imperceptível. Isso obrigou a divisão do intervalo para a análise em duas partes, mas não representou problema, pois ambas continham espessura suficiente para satisfazer as premissas para uma análise cicloestratigráfica.

Acima do intervalo estudado as lâminas dos pares diminuem de espessura, gradando passa para um folhelho laminado. O restante da seção do 7-RL-04-SC está descrito na figura 8, juntamente com o perfil de raios gama.

Testemunho do poço IB-93-RS O testemunho apresenta, na base, um diamictito de aproximadamente $25 \mathrm{~m}$ de espessura e matriz de granulação areia fina a média, em contato discordante com um granito a K-feldspato, representando a base do Grupo Itararé. Possui clastos milimétricos a centimétricos, chegando a decímétricos, imersos na matriz, na maior parte de composição granítica. Clastos de folhelho são menos comuns, aumentando de proporção para o topo. Acima do diamictito ocorre um arenito grosso, de cerca de $1 \mathrm{~m}$ de espessura, com lâminas internas milimétricas de siltito, deformado por dobras convolutas, evidenciando escorregamento.

A partir de $334 \mathrm{~m}$ inicia-se uma sucessão de depósitos rítmicos com gradação normal, o primeiro de arenito muito fino e folhelho e os demais, até a profundidade de $290 \mathrm{~m}$, formados por pares de siltitos laminados e folhelhos.

A passagem das camadas de siltito para folhelhos é gradual, sendo difícil reconhecer seus limites. A espessura das camadas dos siltitos varia de decímetros a metros e dos folhelhos de milímetros a centímetros. Esses ritmitos, como os do 7-RL-04-SC, podem ser classificados como pertencendo a uma seqüência rítmica (Einsele et al. 1991).

As camadas de siltito são marcadas na base por pequenas estruturas de carga, ocasionais clastos pingados milimétricos a submilimétricos e evidências de erosão. Raras ondulações ocorrem no topo de lâminas milimétricas de arenito muito fino internas aos siltitos, na base da seção, mostrando gradação normal ou ripples unidirecionais, onde a parte inferior dos foresets foi preservada. Bioturbações no plano da base das camadas tornamse freqüentes à medida que a espessura diminui para o topo da 


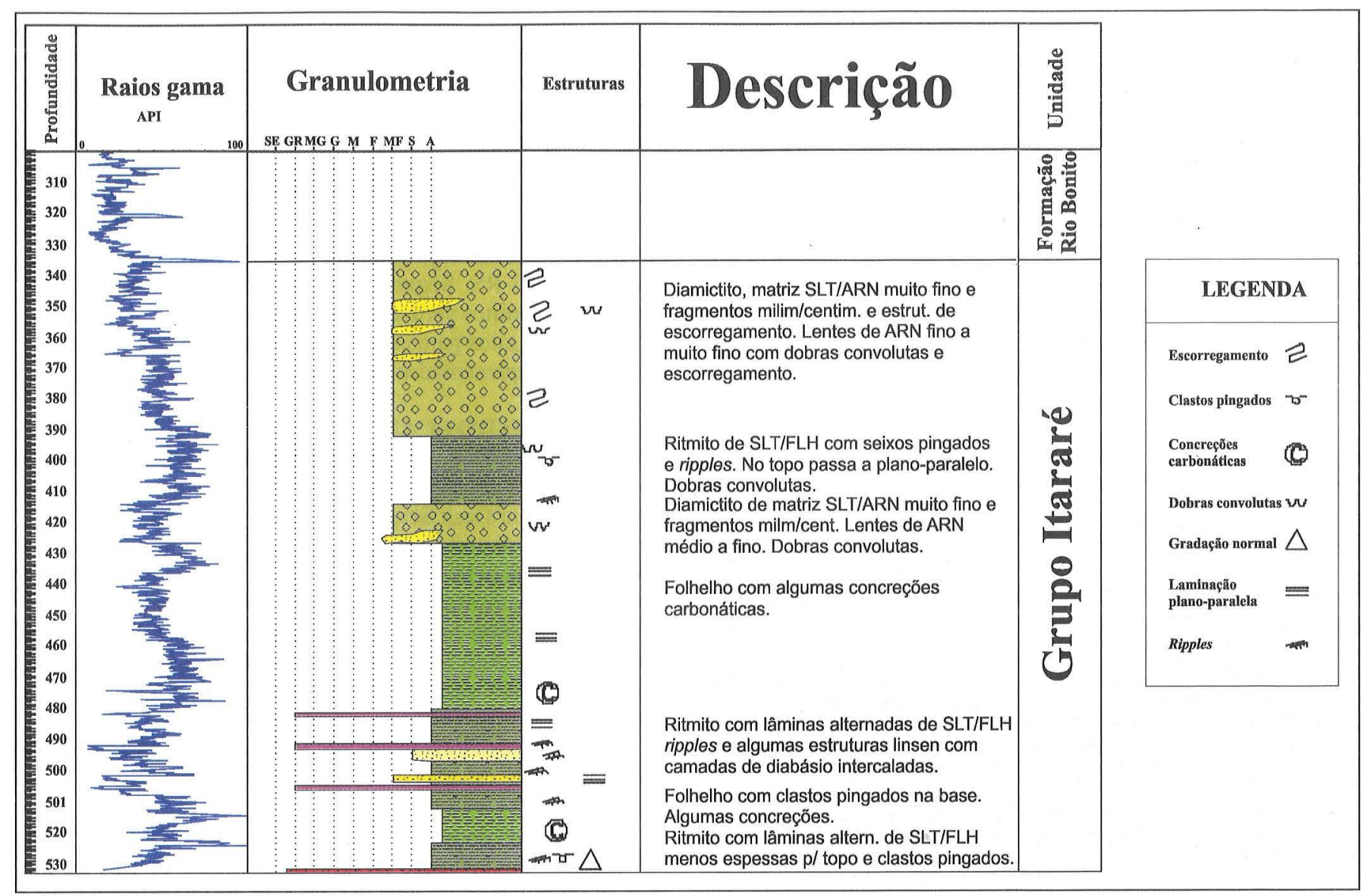

Figura 8-Perfil de raios gama e descrição litológica do poço 7-RL-04-SC

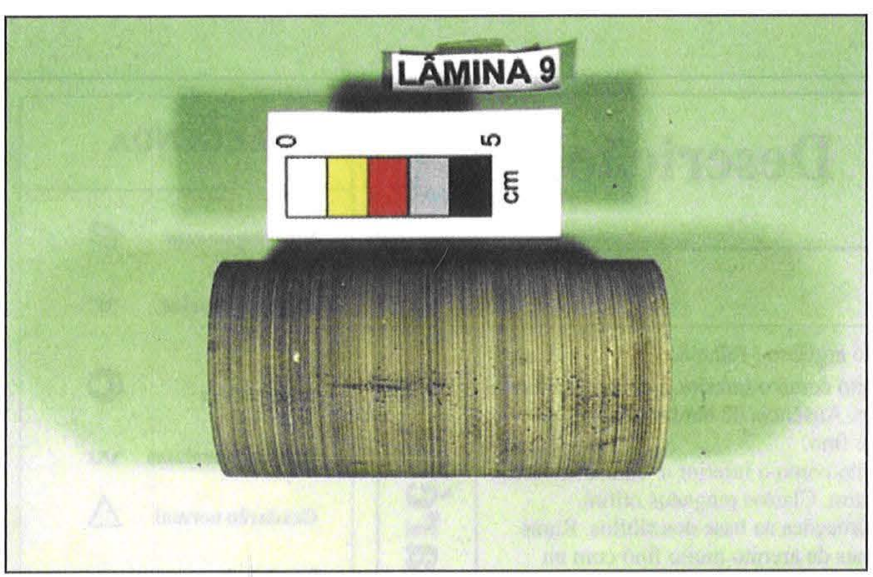

Figura 9 - Trecho do intervalo escaneado do testemunho IB93-RS.

seção, diferenciando o ambiente de deposição desses ritmitos daqueles do 7-RL-04-SC e sugerindo águas mais oxigenadas, com maior conteúdo de nutrientes.

A espessura dos pares torna-se cada vez menor para o topo do testemunho, até tornar-se milimétrica. O intervalo escaneado $(290,08$ a 290,46 m) faz parte dessa intercalação milimétrica (figura 9). Toda a seção do IB-93-RS até a profundidade de 290,46 m apresenta cerca de 561 pares. Especificamente no intervalo escaneado pode-se observar que os pares se agrupam em feixes de três, sete e até mais de vinte pares, com espessura crescente para o topo.

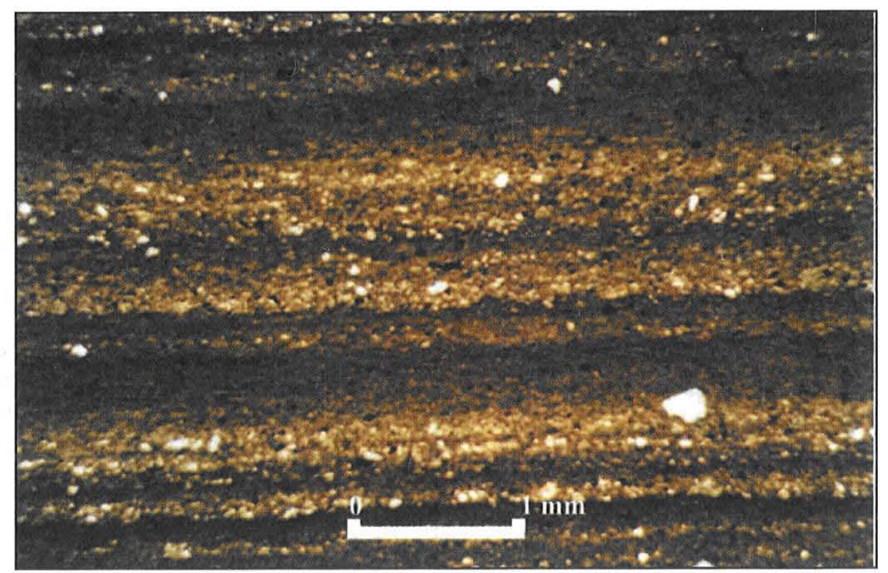

Figura 10 - Fotomicrografia: lâminas milimétricas de siltito (claras), com gradação normal, e de folhelho. Notar a grande quantidade de clastos pingados de quartzo facetado.

Lâminas petrográficas evidenciam vários clastos pingados submilimétricos, depositados principalmente na base das lâminas de siltito (figura 10), eventualmente formando lâminas de chuva de detritos. São constituídos, na maioria, por quartzo facetado e, subordinadamente, intraclastos de arenito intraformacional, onde se reconhecem grãos de plagioclásio pouco alterados (figura 11).

Os ritmitos descritos podem ser classificados como turbiditos. Sua seqüência de empilhamento, com camadas diminuindo de espessura para o topo e raras ondulações, na base do testemunho, mimetizando as características petrográficas e faciológicas ao 
longo da seção, caracteriza um distanciamento gradativo da área fonte, ou subida do nível de base, com os turbiditos tornando-se mais distais e formados por fluxos de baixa densidade.

Depósitos bem semelhantes, a nordeste da área em estudo, foram classificados por Holz (1995a) como "turbiditos distais com granulometria muito fina e fraco componente trativo, não permitindo o desenvolvimento de ondulações", tendo sido formados em lagos de influência glacial, sem contato direto com o gelo.

Machado (1994) identificou no paleovale de Candiota (RS) ritmitos com características semelhantes. Classificou-os como de aspecto várvico, lateralmente correlacionáveis a ritmitos de granulação grossa com estruturas de tração e suspensão. Esses

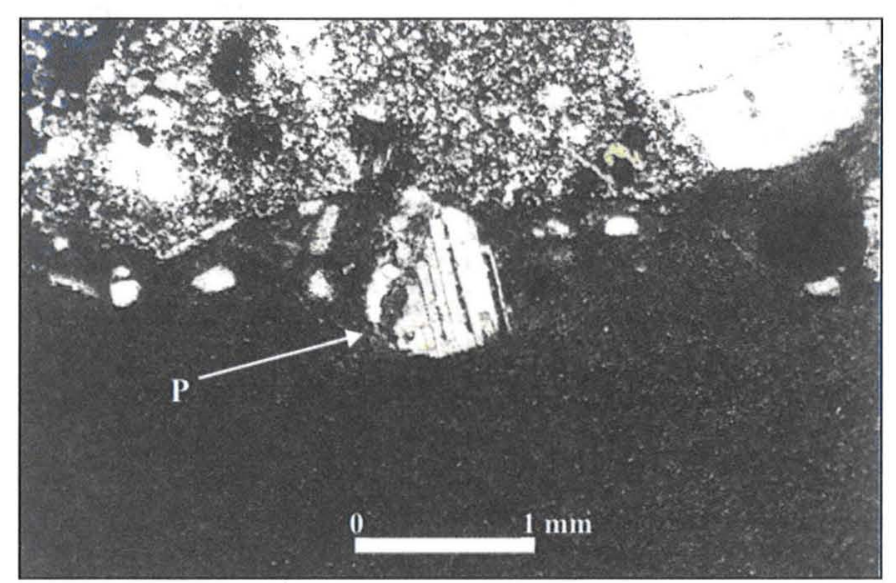

Figura 11 - Fotomicrografia: grão de plagioclásio, muito pouco alterado, consituinte de clasto pingado de arenito. Nicóis cruzados. últimos, segundo o autor, seriam depósitos de frentes de deltas de desembocadura de correntes outwash, sedimentados em pequenos lagos glaciais confinados, correspondendo aos depósitos proximais dos ritmitos várvicos.

As interpretações dadas por Machado (1994) e Holz (1995a) para o ambiente deposicional dos ritmitos estudados por eles assemelham-se à interpretação feita por Aboarrage \& Lopes (1986, apud Lopes, 1995) e por Dias (1993a e 1993c) para o paleovale Leão, em cujo contexto geológico está inserido o testemunho IB-93-RS. Segundo esses autores, o ambiente de deposição dos ritmitos seria o de um fiorde.

O perfil de raios gama e a descrição geral do testemunho IB93-RS estão representados na figura 12.

UTILIZAÇÃO DO SCANNER Para a digitalização dos tes-

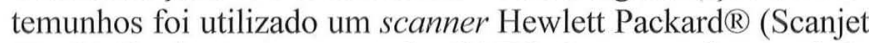
IIcx $($ ) , ligado a um computador CAF®. O scanner é gerenciado com o programa Desk ScanIIR, versão 2.0 (figuras 12 e 13).

Devido às dimensões, os testemunhos foram cobertos por uma caixa de papelão de $32,5 \times 2,4 \mathrm{~cm}$, forrada com feltro de cor preta, em substituição à tampa do scanner, para minimizar a perda de energia luminosa. As bordas do aparelho também foram forradas com feltro preto. Dessa forma, a luminosidade praticamente não variou entre a aquisição de uma imagem e outra.

Antes do posicionamento no scanner, as amostras foram cuidadosamente lavadas e secadas, para evitar falsas cores na imagem.

A fragilidade do testemunho do poço 7-RL-04-SC possibilitou apenas a digitalização de um comprimento de $1,21 \mathrm{~m}$, que teve de ser dividido em dois $(81 \mathrm{~cm}$ e $40 \mathrm{~cm})$ devido à pequena falha, anteriormente citada, o que não representou problema na análise posterior (CEGI-2, nesta publicação).

O testemunho do poço IB-93-RS foi digitalizado em um

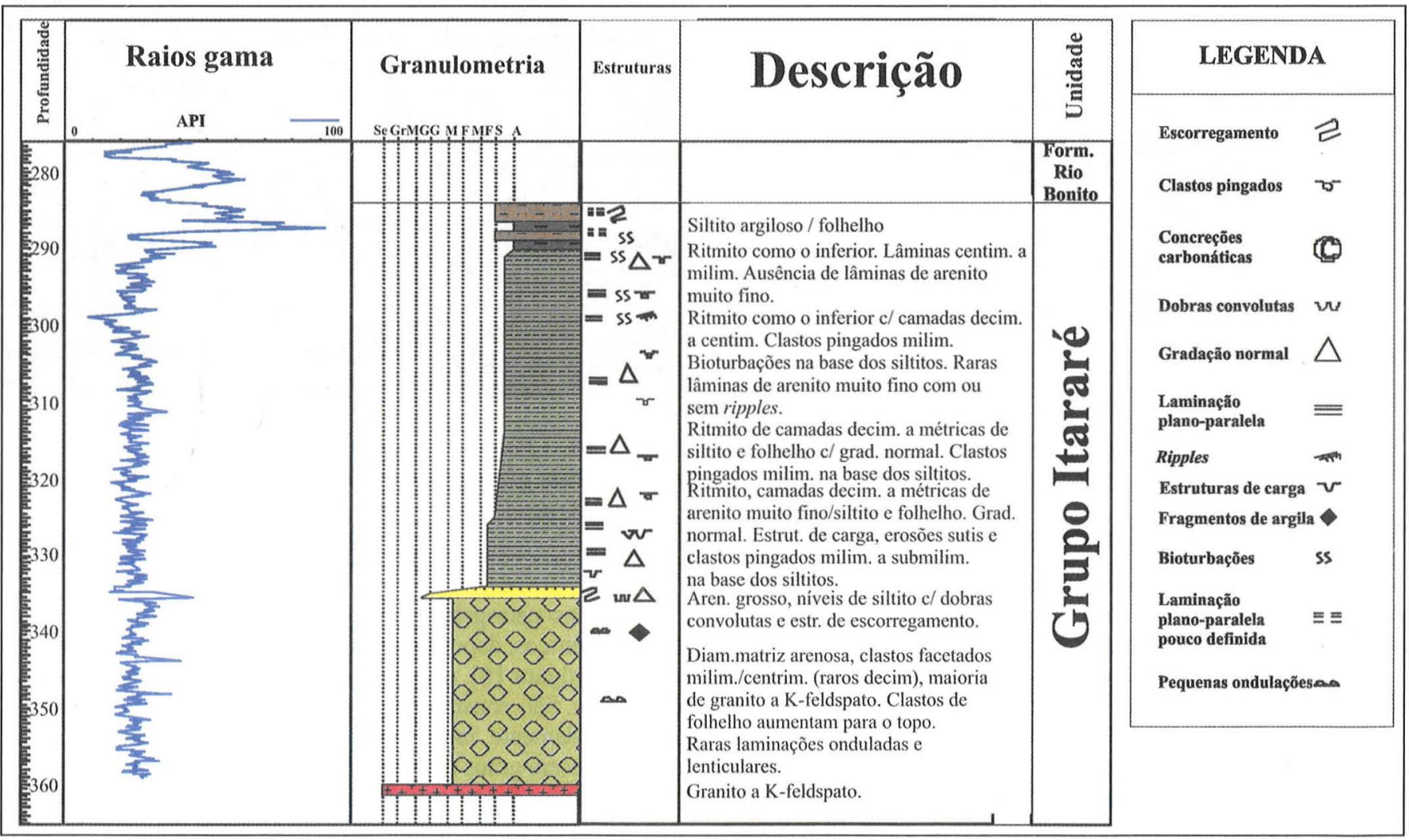

Figura 12 - Perfil de raios gama e descrição litológica do poço IB-93-RS 


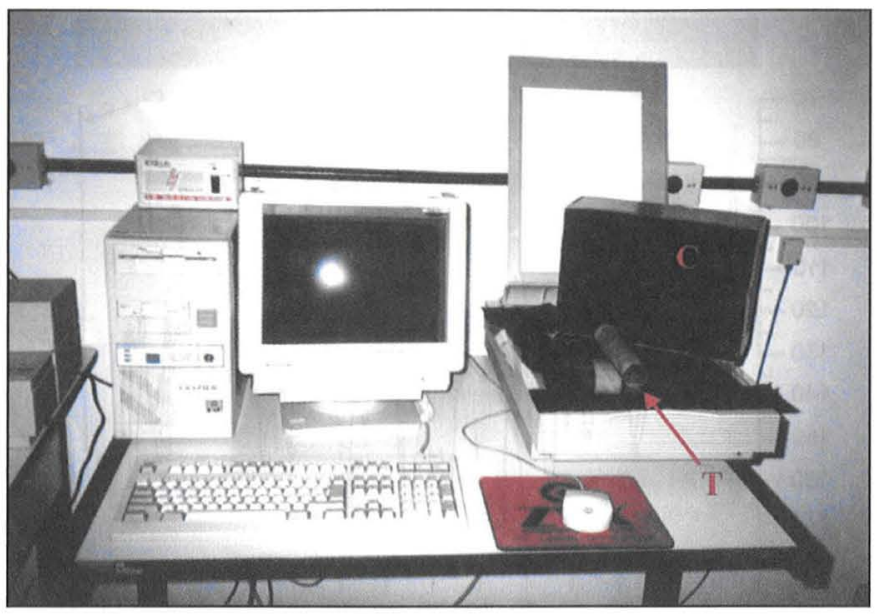

Figura 13 - Aparelhagem utilizada para escanear os testemunhos. Notar o trecho de testemunho (T) sobre o scanner e o feltro preto, no fundo da caixa de papelão (C) e sobre o aparelho.

comprimento de $8,32 \mathrm{~m}$, dividido em três partes. As duas primeiras $(290,82$ a $296,54 \mathrm{~m}$ e 296,60 a $298,82 \mathrm{~m})$ foram separadas devido a uma pequena perda na recuperação durante a perfuração do poço $(6 \mathrm{~cm})$. A terceira parte foi escolhida de um trecho $36 \mathrm{~cm}$ acima, com $38 \mathrm{~cm}$ de comprimento. Como a maior parte da seção do Grupo Itararé nesse poço é formada por uma seqüência rítmica, optou-se por utilizar apenas esse último trecho na análise espectral, que possui laminação milimétrica. As fácies rítmicas próximas à base do testemunho, como foi visto, são semelhantes às das porções superiores, de forma que, sendo as últimas representativas do conjunto em termos da ciclicidade, tornou-se desnecessário utilizar toda a seção, sendo seu conteúdo intrínseco em tempo maior devido às menores taxas de acumulação. Além disso, suas características estacionárias são favoráveis à posterior análise espectral (Weedon 1991).

No scanner, as amostras foram dispostas de forma que as lâminas ficassem em posição horizontal, para o tratamento posterior dos dados. Esse cuidado foi importante, pois, durante a perfuração, a sonda pode desviar da orientação vertical, o que aconteceu no caso do poço 7-RL-04-SC.

O objetivo da digitalização é registrar as variações nas tonalidades de cinza da rocha. Portanto, o número de clastos pingados no testemunho 7-RL-04-SC poderia imprimir ruído nos dados. Além disso, a forma cilíndrica dos testemunhos provoca o escurecimento das laterais em relação ao centro durante a iluminação e uma distorção na imagem. Para minimizar esses efeitos, a área efetivamente digitalizada foi correspondente ao comprimento total e à porção central de cada uma das amostras, tomando-se a precaução de evitar os clastos pingados (figura 15).

A resolução da imagem foi escolhida de acordo com a menor espessura das lâminas. Os atributos do scanner no momento do imageamento foram:

$\Rightarrow$ Modo de fotografia preto e branco ( 8 bits)

$\Rightarrow$ Resolução: $100 \times 100$ pixels por polegada $=3,94$ pixels por milímetro

$\Rightarrow \mathrm{Luz}=207$; sombra $=129 ;$ brilho $=188 ;$ controle $=198$

Como a resolução foi de 3,94 pixels (pontos) a cada milímetro, o intervalo de amostragem (IA) utilizado foi de $1 \mathrm{~mm} /$ 3,94 pontos, ou seja, igual a $0,2538 \mathrm{~mm}$.

De acordo com a teoria da amostragem, a freqüência máxima detectável, ou freqüência de Nyquist, foi: $\mathrm{fN}=1 /(2 . \mathrm{IA}) \Rightarrow$ $\mathrm{fN}=1,97$.

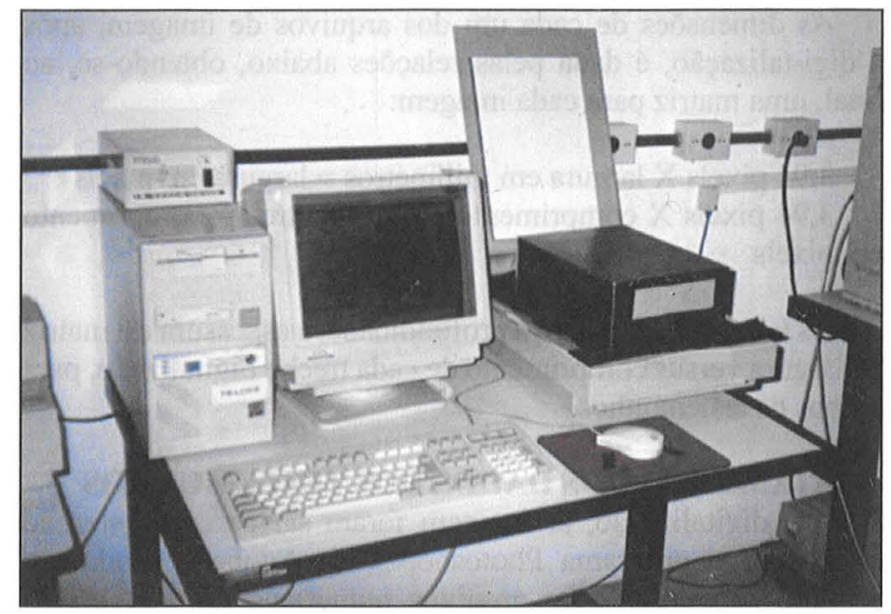

Figura 14 - Scanner coberto com a caixa de papelão. Notar o feltro preto nas laterais do aparelho, impedindo a entrada de luz.

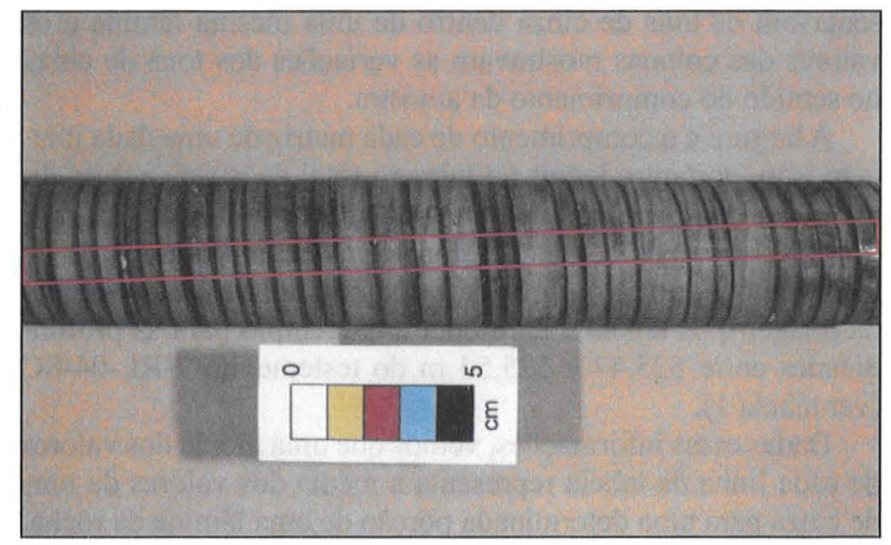

Figura 15 - Trecho do testemunho do poço 7-RL-04-SC, mostrando a área a ser escaneada, em branco.

Tabela 1 - Dados dos trechos digitalizados do testemunho 7 RL-04-SC.

\begin{tabular}{|c|c|c|c|c|c|c|}
\hline \multicolumn{7}{|c|}{ POCO 7-RL-04-SC } \\
\hline & & \multirow{3}{*}{$\begin{array}{l}\text { ESPESSURA } \\
(\mathrm{cm})\end{array}$} & \multicolumn{4}{|c|}{ MATRIZ } \\
\hline \multirow{2}{*}{\multicolumn{2}{|c|}{$\begin{array}{l}\text { PROFUNDIDADE } \\
(\mathrm{m})\end{array}$}} & & Largura & Comprimento & Largura & Comprimento \\
\hline & & & \multicolumn{2}{|c|}{$(\mathrm{cm})$} & \multicolumn{2}{|c|}{ (pixels / $\mathrm{mm}$ ) } \\
\hline & 525,47 a 525,54 & 6.9 & 0,7 & 6.9 & 27 & 271 \\
\hline & 525.54 a 525.66 & 12,4 & 1.0 & 12.4 & 3 & 488 \\
\hline & 525.66 a 525.78 & 11,6 & 1.1 & 11,6 & 43 & 456 \\
\hline & 525,78 a 525,87 & 8,9 & 0,7 & 8,9 & 27 & 350 \\
\hline \multirow{6}{*}{ 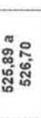 } & $\begin{array}{l}\text { Trecho com ratha } \\
5550\end{array}$ & & & 11 & & \\
\hline & $\frac{525,89 \mathrm{a} 526,00}{52600 \text { a } 52612}$ & $\frac{11,15}{111,}$ & $\frac{0.61}{0.74}$ & $\frac{11,15}{111}$ & $\frac{24}{29}$ & $\frac{439}{437}$ \\
\hline & $\begin{array}{l}526,00 \mathrm{a} 526,12 \\
526,12 \mathrm{a} 526.25 \\
\end{array}$ & 13,31 & 0.53 & 13,31 & 21 & 524 \\
\hline & 526,25 a 526,40 & 14,63 & 1.09 & 14,63 & $\frac{11}{43}$ & 576 \\
\hline & 526,40 a 526,50 & 9.68 & 0,61 & 9,68 & 24 & 381 \\
\hline & 526,50 a 526,70 & 20,35 & 1.04 & 20,35 & 41 & \\
\hline
\end{tabular}

Tabela 2 - Dados do trecho digitalizado e utilizado posteriormente para a análise espectral.do testemunho IB-93-RS.

\begin{tabular}{|c|c|c|c|c|c|c|}
\hline \multicolumn{7}{|c|}{ POCO IB-93-RS } \\
\hline \multirow{3}{*}{\multicolumn{2}{|c|}{$\begin{array}{l}\text { PROFUNDIDADE } \\
(\mathbf{m})\end{array}$}} & \multirow{3}{*}{$\begin{array}{c}\text { ESPESSURA } \\
(\mathrm{cm})\end{array}$} & \multicolumn{4}{|c|}{ MATRIZ } \\
\hline & & & Largura & Comprimento & Largura & Comprimento \\
\hline & & & & $\mathrm{cm})$ & (pix & $\mathrm{s} / \mathrm{mm})$ \\
\hline \multirow{4}{*}{ 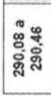 } & a 290,10 & 1,93 & 1,6 & 1,93 & 63 & 76 \\
\hline & 290 & 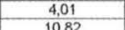 & $\frac{1.63}{16}$ & $\frac{4,01}{1082}$ & 64 & 158 \\
\hline & 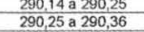 & $\frac{10,82}{11,07}$ & $\frac{1,6}{1,63}$ & $\frac{70,82}{11,07}$ & 63 & $\frac{426}{436}$ \\
\hline & 290,36 a 290,46 & 10,16 & 1.57 & 10.16 & 62 & 400 \\
\hline
\end{tabular}


As dimensões de cada um dos arquivos de imagem, após a digi-talização, é dada pelas relações abaixo, obtendo-se, ao final, uma matriz para cada imagem:

3,94 pixels $X$ largura em milímetros $=$ largura em pixels 3,94 pixels $\mathrm{X}$ comprimento em milímetros $=$ comprimento em pixels

As tabelas 1 e 2 listam a profundidade, a espessura e a matriz de largura versus comprimento de cada trecho digitalizado, para ambos os testemunhos.

\section{TRATAMENTO DOS DADOS DOS TESTEMUNHOS}

Após a digitalização, as imagem foram salvas com extensão .raw, com o programa Photoshop $($, da Adobe $($, sendo em seguida convertidas em arquivos numéricos do tipo ASCII através do programa Rawtab (processável em DOS), criado na Universidade Federal de Santa Maria.

Os dados foram então importados para o programa Excel( $\mathrm{B}$, da Microsoft ${ }^{\circledR}$. Como os testemunhos foram escaneados de forma que as lâminas ficassem em posição horizontal, obteve-se uma matriz (tabelas 1 e 2) em que os valores das linhas representavam os tons de cinza dentro de uma mesma lâmina e os valores das colunas mostravam as variações dos tons de cinza no sentido do comprimento da amostra.

A largura e o comprimento de cada matriz de uma dada imagem, são, portanto, iguais ao número total de pixels nessas dimensões. Por exemplo, uma imagem cujas dimensões são $27 \mathrm{X}$ 271 pixels, após a conversão transforma-se em uma matriz de 27 colunas (largura da imagem) por 271 linhas (comprimento da imagem). A tabela 3 apresenta um exemplo para as profundidades entre 525,47 e $525,54 \mathrm{~m}$ do testemunho 7-RL-04-SC (ver tabela 1 ).

Dadas essas informações, vemos que uma média dos valores de cada linha da tabela representa a média dos valores de tons de cinza para uma determinada porção de uma lâmina da rocha. O cálculo dessa média é importante, pois minimiza os efeitos de grãos pingados de tamanho areia e de outros "ruídos" na imagem, como arranhões, que implicam na variação da cor da amostra. A média dos valores da escala de cinza para cada linha está representada na coluna da direita da tabela 3.

A partir dessas médias foram gerados gráficos Escala de Cinza versus Profundidade para todos os trechos escaneados. O testemunho do poço 7-RL-04-SC, sendo o mais frágil, continha algumas pequenas fraturas que, mesmo após o cálculo da média, ainda provocaram alterações no gráfico de escala de cinza (figura 16). Além disso, as lâminas de siltito desse testemunho contêm ripples internas, unidirecionais, que foram amostradas e tornaram-se visíveis no gráfico. Tais ripples poderiam implicar em ruídos de altíssima freqüência durante a posterior análise dos dados. Essas feições tiveram que ser eliminadas.

Com o auxílio de uma lupa binocular, visualizando-se tanto a amostra quanto o gráfico correspondente em escala real, foi feita a localização dessas feições no gráfico. Após a identificação, procedeu-se à sua eliminação considerando-se o valor médio de tom de cinza em relação aos valores laterais mais próximos. Como resultado, as formas ficaram mais suavizadas do que as serrilhadas anteriores (figura 17). Schaaf \& Thurow (1994) indicam a eliminação das perturbações através de métodos semelhantes. O testemunho do poço IB-93-RS não apresentou esse tipo de problema.

Passoul-se então à junção dos trechos imageados. No momento da utilização do scanner, nem sempre foi possível digitalizar o comprimento exato da amostra. Dessa forma, alguns milímetros do fundo da caixa de papelão foram digitalizados junto com certas amostras. Esses detalhes também foram elimi-

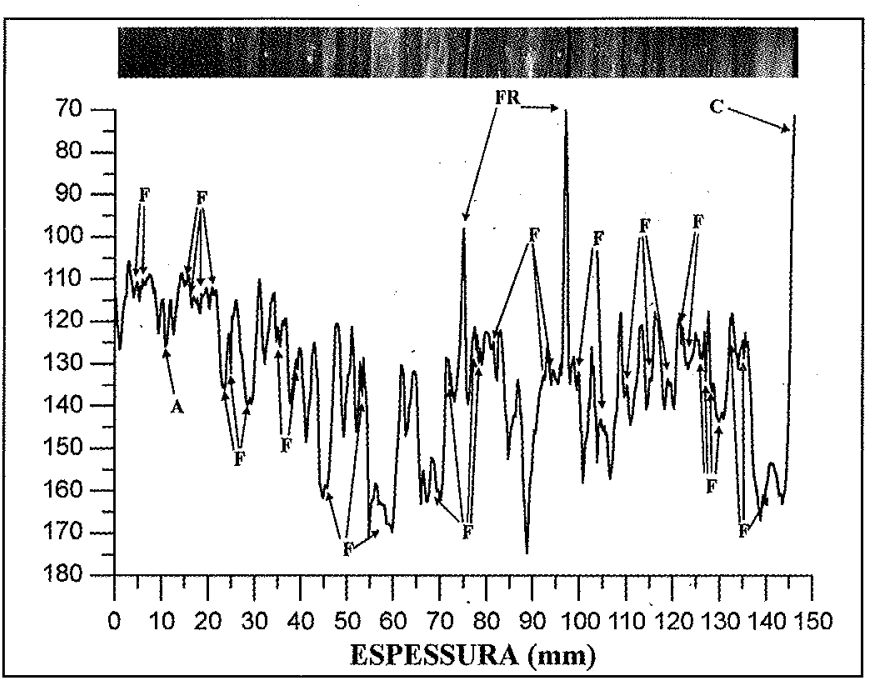

Figura 16 - Gráfico de escala de cinza de um dos trechos escaneados do testemunho do poço 7-RL-04-SC, entre 526,4 e $526,25 \mathrm{~m}$ de profundidade, mostrando foresets $(F)$, fraturas (FR), arranhões (A) e uma porção do fundo da caixa de papelão (C) antes da eliminação.

nados com o auxílio da lupa binocular.

Feito isso, como resultado final foi possível unir os intervalos escaneados em tabelas únicas no Excel $(\mathbb{B}$, três no total, correspondentes aos três intervalos inteiros referenciados nas tabelas 1 e 2, dois do 7-RL-04-SC e um do IB-93-RS, a saber:

a-) poço 7-RL-04-SC $=525,47$ a $525,87 \mathrm{~m}$ e 525,89 a 526,70 $\mathrm{m}$ (figura 18);

\section{b-) poço IB-93-RS $=290,08$ a 290,46 m (figura 19).}

Dados dos perfis de raios gama Os perfis de raios gama dos dois poços foram obtidos através de cópias heliográficas, com a permissão da CPRM. Como ambos são analógicos, houve necessidade de digitalizá-los.

\section{DIGITALIZAÇ̃̃O DOS PERFIS DE RAIOS GAMA}

Primeiramente os perfis foram copiados com o scanner, utilizando-se então o programa Surfer(B) (Surface Mapping System, da Golden Software, Inc.) para digitalizar, na tela do computador, os picos de amplitude das curvas. Durante esse procedimento, as distâncias entre os picos foram transformadas em profundidades reais de perfuração. Os dados foram então gravados sob a forma de arquivo ASCII.

Como a distância entre os picos é variável, essa técnica de digitalização não fornece dados com espaçamento igual, condição obrigatória para a construção de uma série temporal (Schwarzacher, 1987) e para a posterior análise de ciclicidade. Sendo assim, os dados foram eqüidistanciados.

Tratamento dos dados dos perfis de raios gama A reamostragem dos dados para valores eqüidistantes foi feita no programa Matlab® (versão 5 Beta). Como a escala dos perfis era diferente (7-RL-04-SC, 1:500 e IB-93-RS, 1:100), o intervalo de amostragem escolhido foi de $1 \mathrm{~cm}$ para ambos os perfis, pois os valores numéricos de profundidade dos picos, após a digitalização no Surferß, eram bastante aleatórios, variando na casa de unidades de centímetro. $O$ único valor de amostragem factível para a intercalação era o de $1 \mathrm{~cm}$. Os dados reamostrados foram, então, importados para o programa Excel@ @. A tabela 4 contém, 
Tabela 3 - Profundidades, espessuras (baseadas no incremento do intervalo de amostragem de 0,2538 mm) e valores da escala de cinza para o trecho entre 525,47 e 525,54 m do testemunho do poço 7-RL-04-SC. A coluna MÉDIAS apresenta a média dos valores da escala de cinza para cada linha da tabela. Estão representados apenas o inicio e o final da tabela, a qual, completa, possui 271 linhas.

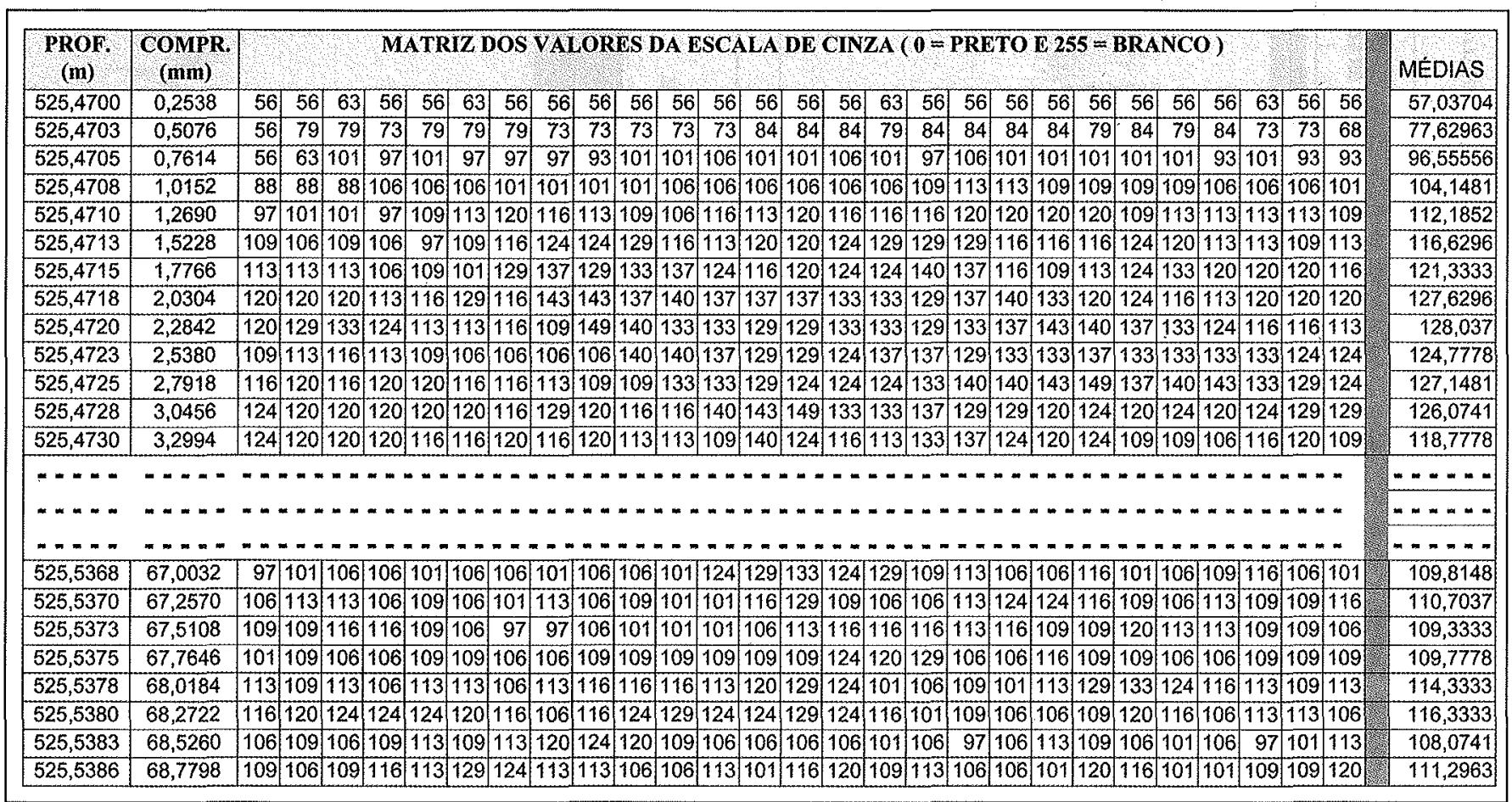

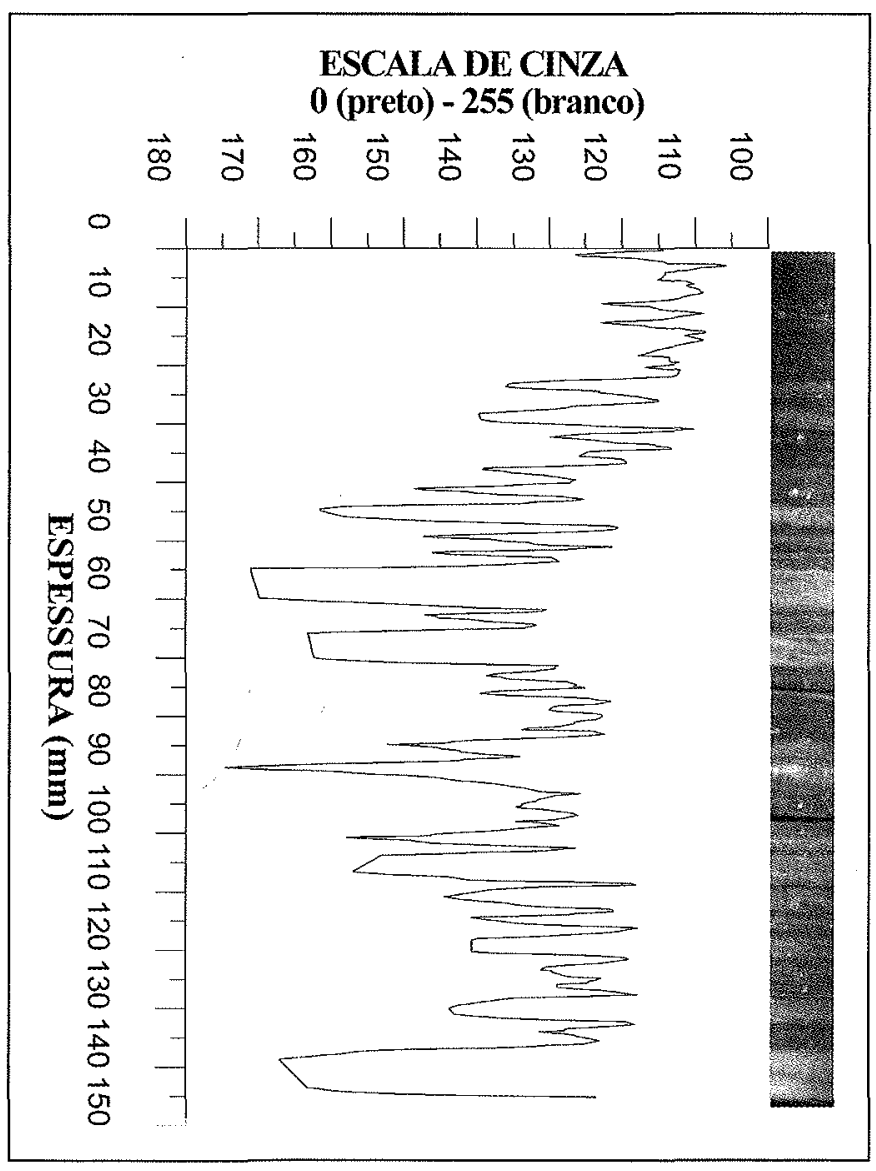

Figura 17 - Gráfico de escala de cinza para o mesmo trecho escaneado do poço 7-RL-04-SC mostrado na figura 16, após as correções. como exemplo, um intervalo do perfil de raios gama do poço IB-93-RS, sem e com reamostragem.

O poço 7-RL-04-SC perfurou algumas camadas de diabásios mesozóicos. Os picos referentes a essas camadas iriam causar ruídos quando da análise de ciclicidade. Logo, houve a necessidade de eliminá-las do perfil.

As figuras 20 e 21 mostram os perfis de raios gama de ambos os poços após todo o tratamento. Notar que, no caso do poço 7-RL-04-SC, a eliminação das camadas de diabásio acarretou mudanças nas profundidades originais, de modo que o perfil após o tratamento teve suas profundidades modificadas a partir de $481,25 \mathrm{~m}$, que é a profundidade da primeira camada de diabásio. Sendo assim, para correlacionar os trechos escaneados do testemunho com o perfil desse último poço é necessário fazer uma correção de $5,98 \mathrm{~m}$ e começar a correlação em $520,36 \mathrm{~m}$, o novo topo do intervalo escaneado do testemunho.

Tratamento dos dados dos perfis de raios gama A reamostragem dos dados para valores eqüidistantes foi feita no programa Matlab® (versão 5 Beta). Como a escala dos perfis era diferente (7-RL-04-SC, 1:500 e IB-93-RS, 1:100), o intervalo de amostragem escolhido foi de $1 \mathrm{~cm}$ para ambos os perfis, pois os valores numéricos de profundidade dos picos, após a digitalização no Surferß, eram bastante aleatórios, variando na casa de unidades de centímetro. O único valor de amostragem factível para a intercalação era o de $1 \mathrm{~cm}$. Os dados reamostrados foram, então, importados para o programa Excel(B). A tabela 4 contém, como exemplo, um intervalo do perfil de raios gama do poço IB-93-RS, sem e com reamostragem.

O poço 7-RL-04-SC perfurou algumas camadas de diabásios mesozóicos. Os picos referentes a essas camadas iriam causar ruídos quando da análise de ciclicidade. Logo, houve a necessidade de eliminá-las do perfil.

As figuras 20 e 21 mostram os perfis de raios gama de ambos 


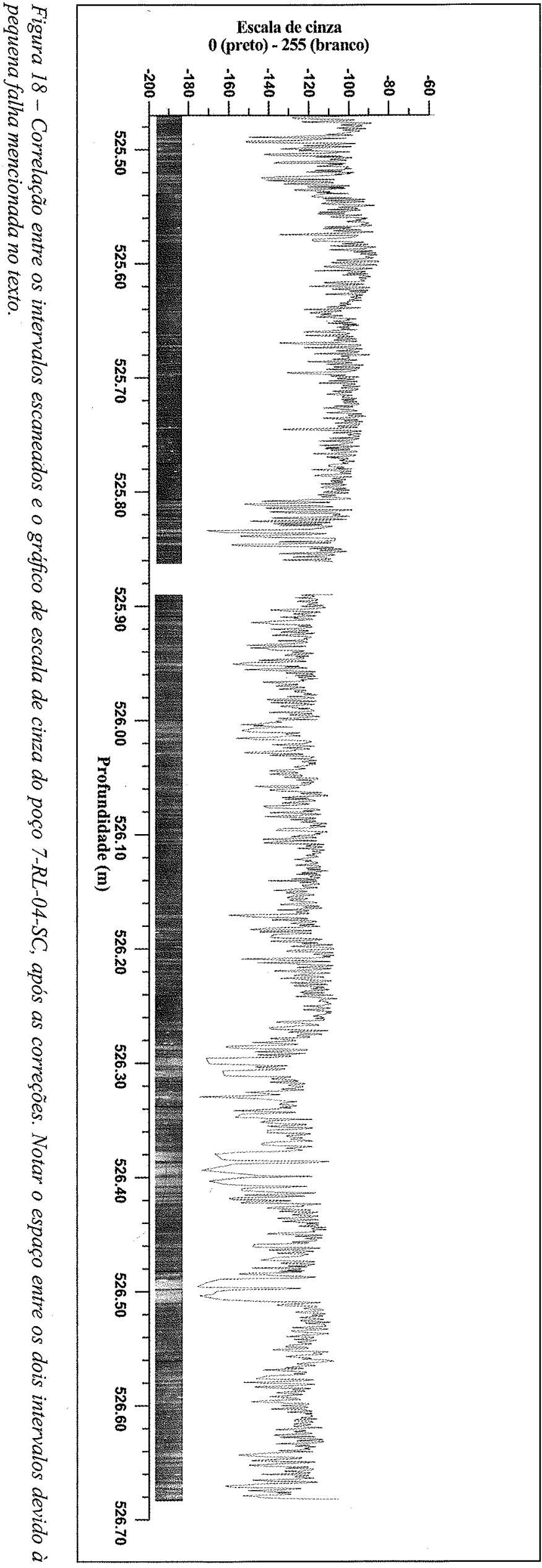

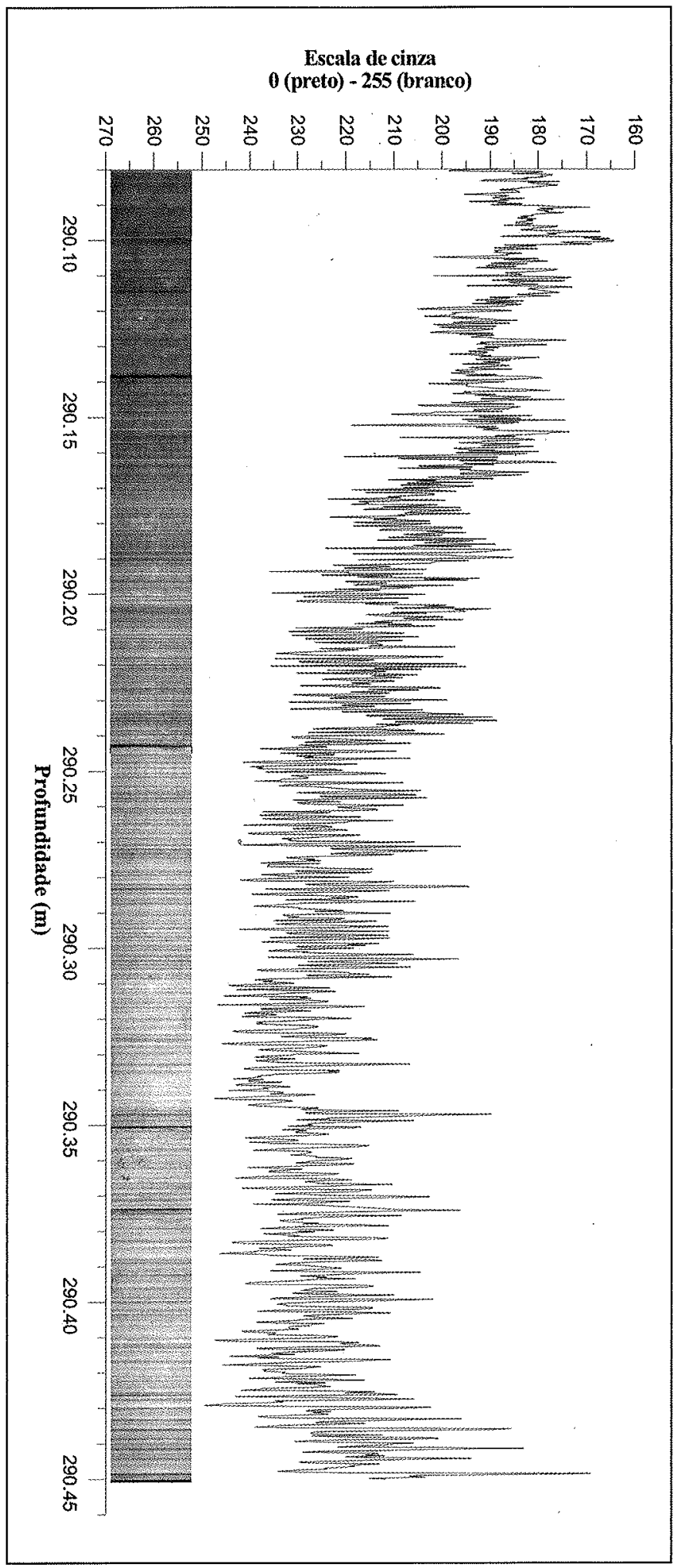

Figura 19 - Correlação entre o trecho escaneado do poço IB93- $R S$ e o respectivo gráfico de escala de cinza.

os poços após todo o tratamento. Notar que, no caso do poço 7-RL-04-SC, a eliminação das camadas de diabásio acarretou mudanças nas profundidades originais, de modo que o perfil após o tratamento teve suas profundidades modificadas a partir de $481,25 \mathrm{~m}$, que é a profundidade da primeira camada de diabásio. Sendo assim, para correlacionar os trechos escaneados do testemunho com o perfil desse último poço é necessário fazer uma correção de $5,98 \mathrm{~m}$ e começar a correlação em $520,36 \mathrm{~m}$, o 


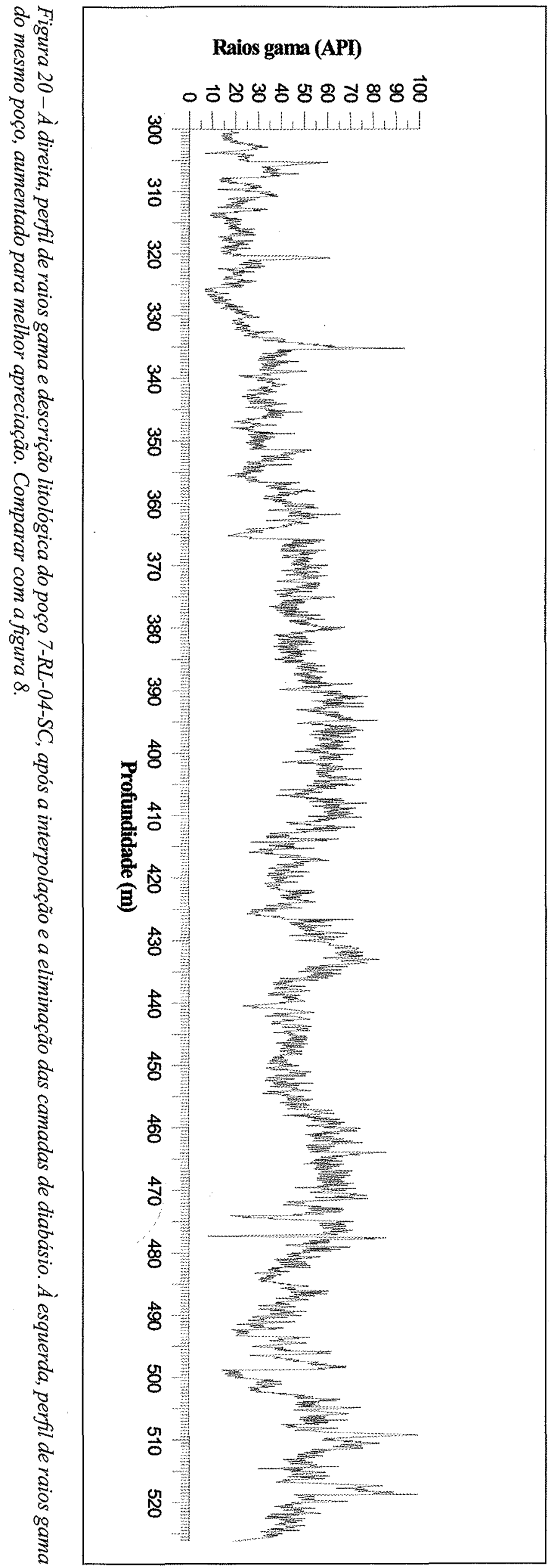

Tabela 4 - Valores do perfil de raios gama do poço IB-93-RS. As duas colunas da esquerda apresentam, respectivamente, os valores de profundidade e de raios gama após a digitalização no programa Surfer $(\mathbb{R}$, antes da reamostragem. As duas colunas da direita exibem um trecho da curva reamostrada com intervalo de $1 \mathrm{~cm}$, correspondente ao intervalo em negrito nas colunas à esquerda.

\begin{tabular}{|l|l|l|l|}
\hline DADOS DO PERFI DERAIOS & \multicolumn{2}{l|}{ DADOS DO RERFI DE RA IOS } \\
GAMA DIGTRALIZADOS & \multicolumn{2}{l|}{ GAMA APOS REAMOSTRAGEM } \\
\hline Profundidade & Valores gama & Profundidade & Valores gama \\
\hline 280,06 & 63,16 & 280,06 & 63,16 \\
\hline 280,16 & 57,6 & 280,07 & 62,604 \\
\hline 280,336 & 64,16 & 280,08 & 62,048 \\
\hline 280,616 & 56,08 & 280,09 & 61,492 \\
\hline 280,716 & 59,88 & 280,1 & 60,936 \\
\hline 280,768 & 59,12 & 280,11 & 60,38 \\
\hline 280,892 & 67,72 & 280,12 & 59,824 \\
\hline 281,096 & 59,88 & 280,13 & 59,268 \\
\hline 281,196 & 63,16 & 280,14 & 58,712 \\
\hline 281,576 & 51,76 & 280,15 & 58,156 \\
\hline 281,728 & 54,8 & 280,16 & 57,6 \\
\hline
\end{tabular}

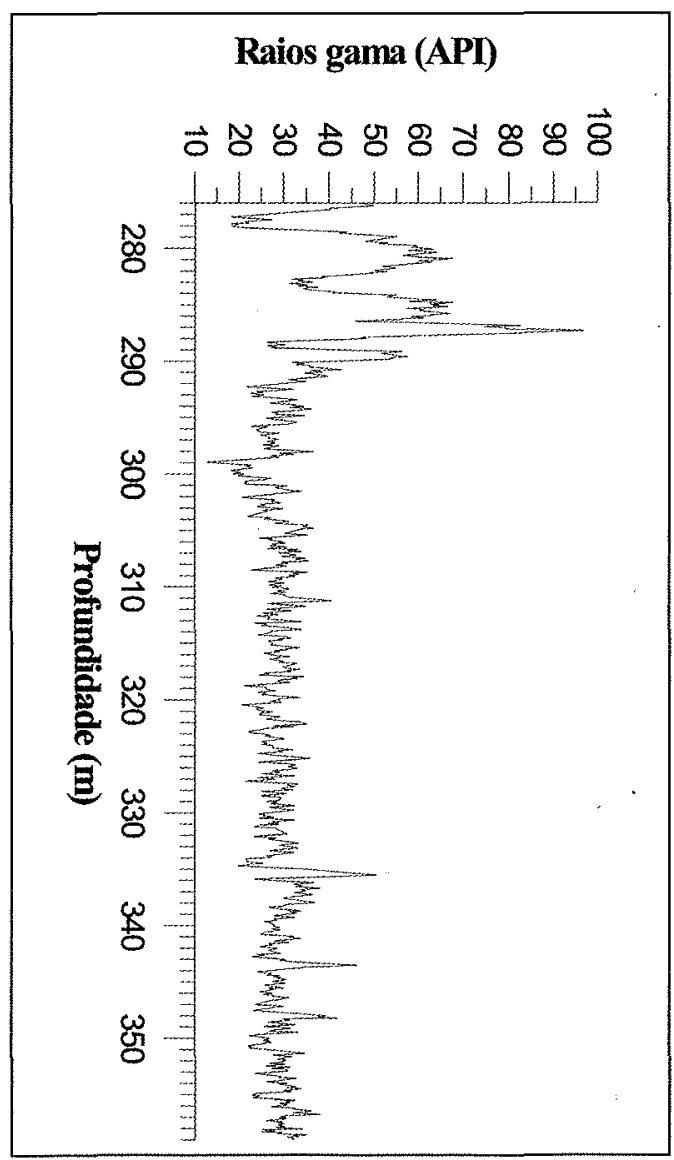

Figura 21 - Perfil de raios gama do poço IB-93-RS, após a interpolação. Comparar com a figura 12. 
novo topo do intervalo escaneado do testemunho.

DISCUSSÃO E CONCLUSÕES Os ritmitos de Santa Catarina têm sido descritos como depositados em lagos glaciais, portanto em ambientes de água doce, por vários autores (MarquesToigo et al., 1989; Machado, 1989; Castro, 1991 e 1995; Castro \& Schneider, 1993; Santos et al., 1996). Porém, a presença dos agregados framboidais de pirita nos ritmitos do testemunho 7RL-04SC acrescenta novos dados à questão, demonstrando que os mesmos foram depositados em água salgada ou salobra. A existência de Botryoccoccus reforça a sedimentação em ambiente misto (Marques-Toigo et al. 1989). Uma interpretação possível seria a de Santos et al. (1996), segundo quais os ritmitos foram. depositados em um inlet costeiro isolado pelas oscilações do nível relativo do mar. Como mostram as evidências, essas oscilações provavelmente ocorriam com grande frequiência.

A interpretação dos ritmitos como originalmente depositados em lagos glaciais também encontra argumento no limite abrupto entre as lâminas de siltito e de folhelho, característica comum em varvitos, onde a estratificação da água do lago, devida à diferença na temperatura, provoca a sedimentação dos grossos, no caso o silte, no verão, e das argilas no inverno, quando a temperatura da água se homogeneíza e a água perde a estratificação. Contatos abruptos dessa natureza normalmente ocorrem pela ausência de floculação dos finos, que, em água salgada ou salobra, decantariam logo após os mais grossos, formando depósitos com gradação normal.

Análises realizadas no laboratório de difratometria de raios $\mathrm{X}$ da UFRGS mostraram que os minerais dos ritmitos são ilita, clorita, ortoclásio, albita, microclínio, quartzo e moscovita. Segundo Ramos \& Formoso (1975), a área fonte, o clima e o relevo seriam os responsáveis pela presença da ilita, da clorita e dos feldspatos, abundantes tanto nas rochas do Grupo Itararé quanto nas cristalinas do embasamento. Chamley (1989) reportou que as argilas dos tilitos e varvitos da Nova Inglaterra, no leste do Canadá, são ricas em ilita e clorita, normalmente encontradas na área fonte dos sedimentos. Segundo esse autor, a floculação de argilominerais acontece durante o transporte do continente para o mar, quando experimentam mudanças de salinidade, $\mathrm{pH}$ e outras características fisico-químicas, passando do ambiente continental, depletado em ions dissolvidos, para o ambiente marinho, quimicamente mais concentrado. Ilitas e cloritas apresentam maior dificuldade de floculação porque têm muita carga superficial, em comparação com as caulinitas, por exemplo, aumentando a repulsão e tornando mais difícil a floculação. Como os ritmitos se depositaram em ambiente de águas mistas, é possível que a floculação fosse inibida e só ocorresse nas porções mais abertas da bacia.

Em relação às duas escalas utilizadas no trabalho, a dos perfis de raios gama e a dos testemunhos, conforme comentado anteriormente, elas concernem a escalas de análise diferentes. Perfis de raios gama digitais costumam trabalhar com amostragens da ordem de, no mínimo, $20 \mathrm{~cm}$, não registrando variações menores que esta espessura nas rochas. Existem hoje perfis de raios gama de alta resolução, mas que contemplam amostragens de até $1,5 \mathrm{~cm}$. Estas resoluções correspondem aos limites físicos das ferramentas de perfilagem. Portanto, os eventos geológicos de menor espessura ficam sempre suavizados e o perfil tende a responder com a média dos valores de argilosidade da rocha perfilada. No caso de um ritimito, o perfil responde como siltito ou folhelho, dependendo da variação de espessura das lâminas. Os perfis empregados neste estudo eram analógicos e foram digitalizados para que as análises pudessem ser realizadas. A amostragem mínima possível, pelos motivos já citados, foi a de $1 \mathrm{~cm}$, correspondente à menor distância entre picos nos perfis originais, ou seja, à menor variação detectada por eles originalmente. Deve-se, logo, ter em mente a escala de trabalho antes de decidir sobre o método de amostragem.
No que concerne aos trechos escaneados dos testemunhos, a utilização do scanner e da escala de cinza tem sido relativamente utilizada por outros autores. Dos primeiros a usar essa metodologia, Ripepe et al. (1991), estudando a ciclicidade dos varvitos eocênicos submilimétricos da Formação Green River (EUA), produziram réplicas de acetato de 3 a $4 \mathrm{~cm}$ de comprimento a partir de um testemunho, as quais digitalizaram e converteram em valores numéricos da escala de cinza. Em outro estudo, Schaaf \& Thurow (1994 e 1997) escanearam dois testemunhos (60 e 100 m), amostrados pelo Ocean Drilling Program (ODP) na Bacia de Santa Bárbara, Califórnia (EUA), em intervalos de 20 a 30 $\mathrm{cm}$, obtendo arquivos contínuos na escala de cinza. Com a transformada rápida de Fourier, interpretaram ciclicidades nas escalas de séculos e anos, anteriormente não observáveis. Jaminski et al. (1998) analisaram as variações climáticas do Devoniano da Bacia Central Appalachian (EUA) da mesma forma; através da conversão da litologia para valores da escala de tons de cinza. Porém, trabalharam com folhelhos, não obtendo, portanto, contrastes de cor diretamente da rocha. Fizeram então radiografias dos testemunhos, as quais digitalizaram com um scanner, obtendo um registro das variações na composição a partir das diferenças de densidade entre porções mais ricas em matéria orgânica, carbonatos ou siliciclásticos. Von Rad et al. (1999) utilizaram essa mesma metodologia para estudar a ciclicidade de varves do Holoceno do Mar da Arábia. De forma semelhante à metodologia descrita nesse artigo, também escanearam diretamente o testemunho.

Portanto, a técnica de transformar dados litológicos em valores de tons de cinza tem sido utilizada com sucesso. É uma metodologia de fácil aplicação, permitindo a aquisição de dados para análise cicloestratigráfica de maneira confiável e eficaz. Isso ficou demonstrado pela exatidão entre os valores dos gráficos de escala de cinza obtidos para os dois poços e as lâminas de siltito e folhelho dos intervalos escaneados, possibilitando desde a visualização de lâminas individuais submilimétricas até os foresets das pequenas ripples dos siltitos.

Duas sugestões para trabalhos futuros seriam: a análise de outros poços da Bacia do Paraná, de forma a testar a eficiência do método e a existência de evidências de deposição em ambiente marinho ou salobro nos ritmitos de outras posições da Bacia; e o teste do método em seqüências de rochas não apenas siliciclásticas, com acamamento rítmico sub-centimétrico, como, por exemplo, evaporitos, rochas carbonatadas, ou rochas depositadas em ambiente tipo playa-lake. O sinal climático nestas rochas é muito evidente e, no caso das carbonatadas, a grande presença de fósseis pode oferecer a ocasião para um bom detalhamento do tempo e do ambiente de deposição de cada par ou grupo de camadas presente nos ritmitos.

Finalizando, os métodos apresentados auxiliam a eficiência da cicloestratigrafia como ferramenta de análise e refinamento cronoestratigráfico. Como afirmaram Schaaf \& Thurow (1994 e 1997), a análise de imagens digitais terá no futuro um papel fundamental na descrição e na interpretação de testemunhos e amostras de rocha.

Agradecimentos À PETROBRAS pela oportunidade de fazer este estudo. À CPRM pela cessão dos dados de poços e suas descrições. Ao Prof. Dr. Luis Fernando De Ros pelo auxílio na descrição das lâminas petrográficas e pelas explanações a respeito dos argilominerais e dos frambóides de pirita. Ao geofísico Fernando S. Rodrigues, pelo auxílio com o programa Matlabß. Aos colegas da pós-graduação da UFRGS, pela descrição em conjunto do testemunho do poço 7-RL-04-SC. Ao colega Saulo Ferreira Santos, pelos originais de sua descrição desse testemunho e pelas discussões sobre o mesmo. E à colega Ariane da Silveira, pelas discussões e colaboração durante a descrição do testemunho do poço IB-93-RS, na UNISINOS. 


\section{Referências}

Azambuja Filho, Nilo Chagas de. 1990. The Oligo-Miocene turbidites and associated facies of the Campos Basin, offshore Brazil. London, United Kingdom. 456p. PhD Thesis, University of London.

Berner, Robert A. 1984. Sedimentary pyrite formation: an update. Geochimica et Cosmochimica Acta, v.48, p. 605-615.

Bloch, John \& Krouse, H. Roy. 1992. Sulfide diagenesis and sedimentation in the Albian Harmon Member, Western Canada. The of Sedimentary Petrology, v.62, n. 2, p. 235-249, March.

Canuto, José Roberto. 1993. Facies e ambientes de sedimentação da Formação Rio do Sul (Permiano), Bacia do Paraná, na região de Rio do Sul, Estado de Santa Catarina. São Paulo, 164p. Tese de Doutorado em Geociências, Instituto de Geociências, Universidade de São Paulo.

Castro, Joel Carneiro de. 1980. Fácies, ambientes e seqüências deposicionais das formações Rio do Sul e Rio Bonito, leste de Santa Catarina. In: SBG, Cong. Bras. Geol, 31, Balneário de Camburiu. Anais, v.1, p. 283-299.

Castro, Joel Carneiro de. 1991. A evolução dos sistemas glacial, marinho e deltaico das formações Rio do Sul e Rio Bonito/Mb. Triunfo (Eopermiano), sudeste da Bacia do Paraná. Rio Claro, $147 \mathrm{p}$. Tese de Doutorado em Geociências, Instituto de Geociências e Ciências Exatas, Universidade Estadual Paulista.

Castro, Joel Carneiro de. 1995. Ciclos ou sequiências no arcabouço cronoestratigráfico da sucessão Itararé (Formação Taciba) - Rio Bonito (Membro Triunfo), Bacia do Paraná. In: Simpósio Sobre Cronoestratigrafia da Bacia do Paraná, 2, Porto Alegre. Boletim de Resumos Expandidos, p. 66-70.

Castro, Joel Carneiro de \& Schneider, Ruben L. 1993. Cronoestratigrafia e evolução paleogeográfica da sucessão Itararé-Rio Bonito (Membro Triunfo), SE da Bacia do Paraná. In: Simpósio Sobre Cronoestratigrafia da Bacia do Paraná, 1, Rio Claro. Boletim de Resumos, p. 37-38.

Cazzulo-Klepzig, Miriam; Guerra-Sommer, Margot \& Marques-Toigo, Marleni. 1980. Estudo macro e microflorístico do Grupo Itararé (Bacia do Paraná), Rio Grande do Sul. In: SBG, Cong. Bras. Geol., 31., Balneário de Camboriú, Anais, v.5, p. 3027-3040.

Chamley, Hervé. 1989. Clay sedimentology. Berlin: Springer-Verlag. $623 \mathrm{p}$.

Chatfield, C. 1989. The analysis of time series - an introduction. London: Chapman and Hall. $241 \mathrm{p}$.

Cottle, R. A. 1989. Orbitally mediated cycles from the Turonian of southern England: their potential for high-resolution stratigraphic correlation. Terra Nova, v.1, n. 5, p. 426-436.

Daemon, Roberto Ferreira \& Quadros, Luis Padilha de. 1970. Bioestratigrafia do Neopaleozóico da Bacia do Paraná. In: SBG, Cong. Brás. Geol., 24., Brasília. Anais', p. 359-412.

Dias, Maria Elice Rosa. 1993a. Palinologia do Grupo Itararé no Rio Grande do Sul. Porto Alegre, 227p. Tese de Doutorado em Geociências, Instituto de Geociências, Universidade Federal do Rio Grande do Sul.

Dias, Maria Elice Rosa. 1993b. Palinologia do Grupo Itararé no Rio Grande do Sul, Permiano da Bacia do Paraná, Brasil. In: SBP, Cong. Brás. Paleo., 13, São Leopoldo. Boletim de Resumos. São Leopoldo: CPRM, p. 63.
Dias, Maria Elice Rosa. 1993c. Associações microflorísticas dos paleovales do Grupo Itararé no Rio Grande do Sul, Permiano da Bacia do Paraná, Brasil. Pesquisas, v.20, n. 2, p. 132-140.

Einsele, Gerhard; Ricken, Werner \& Seilacher, Adolf. 1991. Cycles and events in stratigraphy - basic concepts and terms. In: Einsele, Gerhard; Ricken, Werner \&'Seilacher, Adolf. (ed.). Cycles and events in stratigraphy. Berlin: Springer-Verlag. p. 1-19.

França, Almério Barros. \& Potter, Paul E. 1988. Estratigrafia, ambiente deposicional e análise de reservatório do Grupo Itararé (Permocarbonífero), Bacia do Paraná (parte 1). Boletim de Geociências da Petrobras, v.2, n. 2/4, p. 147-191, abril/dezembro.

Guerra-Sommer, Margot \& Cazzulo-Klepzig, Miriam. 1993. Biostratigraphy of the Southern Brazilian Neopaleozoic Gondwana Sequence: a preliminary palaeobotanical approach. In: Congrès International de la Stratigraphie et Géologie du Carbonifère et Permian, 12, Buenos Aires. Compte Rendu, v.2, p. 61-72.

Holz, Michael. 1995a. O intervalo gonduânico basal (Eo-Permiano) da Bacia do Paraná na região nordeste do Rio Grande do Sul - um exercicio de estratigrafia. Porto Alegre, 256 p., 2 volumes. Tese de Doutorado em Geociências, Instituto de Geociências, Universidade Federal do Rio Grande do Sul.

Holz, Michael. 1995b. Proposta de arcabouço cronoestratigráfico de terceira ordem para o pacote eo-permiano da Bacia do Paraná no Rio Grande do Sul. In: Smipósio Sobre Cronoestratigrafia da Bacia do Paraná, 2, Porto Alegre. Boletim de Resumos Expandidos, p. 91-97.

Jaminski, J.; Algeo, T.; Maynard, B. \& Hower, J. C. 1998. Climatic origin of $\mathrm{dm}$-scale compositional cyclicity in the Cleveland Member of the Ohio Shale (Upper Devonian), Central Appalachian Basin U.S.A. In: Schieber, J. (ed.). 1998. Recent progress in shale research. New York: Schweizerbart'sche. p. 217-242.

Lopes, Ricardo da Cunha. 1995. Arcabouço aloestratigráfico para o intervalo "Rio Bonito-Palermo" (Eopermiano da Bacia do Paraná), entre Butiá e São Sepé, Rio Grande do Sul. Porto Alegre, 254p. Dissertação de Mestrado em Geociências, Centro de Ciências Tecnológicas, Universidade do Vale do Rio dos Sinos.

Lopes, Ricardo da Cunha; Holz, Michael; Piccoli, A. E. M.; DiasFabrício, Maria E.; Cazzulo-Klepzig, Miriam.; Marques-Toigo, Marleni \& Guerra-Sommer, Margot. 1991. Stratigraphical revision of the Itarare Group (Lower Permian), Parana Basin, southern Brazil. In: International Congress on Carboniferous and Permian Geology and Stratigraphy, 12, Buenos Aires. Abstracts.

Machado, Luís Cláudio Ribeiro. 1989. Fácies e arcabouço estratigráfico do Grupo Itararé em Alfredo Wagner (SC) - Sedimentação periglacial. Ouro Preto, 164p. Dissertação de Mestrado em Geociências, Departamento de Geologia, Universidade Federal de Ouro Preto.

Machado, Marco Antônio Pinheiro. 1994. O degelo final permiano e o seu registro geológico na borda sudeste da Bacia do Paraná (Paleovale de Candiota - RS). Porto Alegre, 165p. Dissertação de Mestrado em Geociências, Instituto de Geociências, Universidade Federal do Rio Grande do Sul.

Marques-Toigo, Marleni. 1991. Palynobiostratigraphy of the Southern Brazilian Neopalaeozoic Gondwana Sequence. In: Ulbrich, H. \& Rocha Campos, A. C. (ed.). Gondwana Seven., São Paulo, 1991. Proceedings. São Paulo: Instituto de Geociências da Universidade de São Paulo., p. 503-515. 
Marques-Toigo, Marleni; Dias-Fabrício, Maria E.; Guerra-Sommer, Margot; Cazzulo-Klepzig, Miriam. \& Piccoli, A. E. M. 1989. Afloramentos da área de Trombudo Central, Permiano inferior, Santa Catarina: palinologia, icnologia e sedimentologia. In: SBP, Cong. Bras. Paleo., 11, Curitiba. Anais, v.1, p. 125-150.

Pike, Jennifer \& Kemp, Alan E. 1996. Preparation and analysis techniques for studies of laminated sediments. In: Kemp, Alan E. (ed.). 1996. Palaeoclimatology and Palaeoceanography from Laminated Sedimens. London: The Geological Society. p. 37-48.

Postma, Dieke. 1982. Pyrite and siderite formation in brackish and freshwater swamp sediments. American Journal of Science, v.282, p. 1151-1183, October.

Raiswell, R. 1982. Pyrite texture, isotopic composition and the avalability of iron. American Journal of Science, v.282, p. 12441263 , October.

Ramos, Adriano Nunes \& Formoso, Milton Luiz Laquintinie. 1975. Argilominerais das rochas sedimentares da Bacia do Paraná. Ciência, Técnica e Petróleo, n.9. Petrobras/Cenpes/Dintep. Rio de Janeiro.

Ripepe, M. 1991. Albian pelagic rhythms (Piobbico core). Journal of Sedimentary Petrology, v.61, n. 7, p. 1164-1172, December.

Rossetti, Enio Luiz. 1996. Estratigrafia de seqüências de alta resolução obtida com imageamento de linhas sísmicas na fase rift da Bacia Potiguar (Eocretáceo). Porto Alegre, 151p. Dissertação de Mestrado em Geociências, Intituto de Geociências, Universidade Federal do Rio Grande do Sul.

Santos, P. R. dos; Rocha-Campos, A. C. \& Canuto, J. R. 1996. Patterns of late Paleozoic deglaciation in the Paraná Basin, Brazil. Palaeogeography, Palaeoclimatology, Palaeoecology, Amsterdam, v.125, p. $165-184$.

Schaaf, Michael \& Thurow, Jürgen. 1994. A fast and easy method to derive highest-resolution time-series datasets from drillcores and rock samples. Sedimentary Geology, v.94, p. 1-10.

Schaaf, Michael \& Thurow, Jürgen. 1997. Tracing short cycles in long records: the study of inter-annual to inter-centennial climate change from long sediment records, examples from the Santa Barbara Basin. Journal of the Geological Society, v.154, p. 613622, London.

Schwarzacher, W. 1987. The analysis and interpretation of stratification cycles. Paleoceanography, v.2, n. 1, p. 79-95, February.

Silva, José Guilherme Rodrigues da. 2001. Estudo de cicloestratigrafia nos depósitos eopermianos do Grupo Itararé, Bacia do Paraná, nos estados de Santa Catarina e do Rio Grande do Sul, baseado em dados de testemunho e de perfis de raios gama. Porto Alegre, 228p. Dissertação de Mestrado em Geociências, Instituto de Geociências, Universidade Federal do Rio Grande do Sul.

Silveira, Ariane Santos da. 2000. Estratigrafia de seqüências e evolução peleoambiental da sucessão permiana (Sakmariano-Eokazamiano) da Bacia do Paraná, entre Rio Pardo e Mariana Pimentel. Porto Alegre, 131p. Dissertação de Mestrado em Geociências, Centro de Ciências Exatas e Tecnológicas, Universidade do Vale do Rio dos Sinos.

Tomazelli, Luiz José \& Soliani Jr., Enio. 1982. Evidências de atividade glacial no Paleozóico Superior do Rio Grande do Sul, Brasil. In: SBG, Cong. Bras. Geol., 32, Salvador. Anais, v.4, p. 1378-1391.

Von Rad, Ulrich; Schaaf, Michael; Michels, Klaus H.; Schulz, Hartmut; Berger, Wolfgang H. \& Sirocko, Frank. 1999. A 5000-yr record of climate change in varved sediments from the oxygen minimum zone off Pakistan, Northeastern Arabian Sea. Quaternary Research, v.51, p. 39-53.

Weedon, G. P. 1991. The spectral analysis of stratigraphic time series. In: Einsele, Gerhard; Werner, Ricken \& Seilacher, Adolf. (ed.). 1991. Cycles and events in stratigraphy. Berlin: Springer-Verlag. p. 840854. 